Studia Anglica Posnaniensia 47/4, 2012

doi:10.2478/v10121-012-0010-z

\title{
LINGUISTICS
}

\section{TYPES OF LEXICAL COMPLEXITY IN ENGLISH: SYNTACTIC CATEGORIES AND THE LEXICON}

\author{
JOHN ANDERSON
}

Methoni, Greece

\begin{abstract}
This study focuses on minimal (non-compound, non-phrasal) signs that are nevertheless internally complex in their syntactic categorization. Sometimes this is signalled by morphology - affixation or internal modification. But there are also conversions. In terms of categorial structure, we can distinguish between absorptions, where the source of the base is associated with a distinct category, and incorporation, where the base is categorially constant. Incorporation is thus typically reflected in inflectional morphology. Absorption may be associated with morphological change or conversion - with retention of the base in a different categorization. But categorial complexity may be nonderived, covert: the categorial complexity of an item is evident only in its syntax and semantics.
\end{abstract}

\section{Introduction}

Among lexical items that display complex syntactic categorizations, Anderson (2011 a, b) distinguishes between what is called there "absorptions" and "incorporations" (see too e.g. Anderson 2006: §9.2). ${ }^{1}$ The complex categorizations associated with these are regulated by lexical redundancies. In the former type, a minimal syntactic sign belonging to one syntactic category is associated with

I am grateful to Fran Colman for her comments on various versions of what is presented in what follows. In a way, the present offering can be seen as a rather distant sequel to Anderson (1984). 
a different categorization. Thus a lexical verb, represented by $\{\mathrm{P} ; \mathrm{N}\}$ in the notation of Anderson $(2011 \mathrm{a}, \mathrm{b})$, may be associated with a complex in which $\{\mathrm{P} ; \mathrm{N}\}$ has absorbed $\{\mathrm{P}\}$, finiteness. Finiteness is the capacity to head a potentially independent predication. The categorization for a finite verbal is manifested independently by a "modal" in English, as in may leave. In the case of finite leave(s)/left the finite is based on a verbal categorization that is otherwise nonfinite, as with leave in may leave; in leave(s)/left the non-finite $\{\mathrm{P} ; \mathrm{N}\}$ has absorbed the finite $\{\mathrm{P}\}$.

Categorizations such as $\{\mathrm{P}\}$ and $\{\mathrm{P} ; \mathrm{N}\}$ are distinguished by combinations of primary features: the representation for may is simple, involving uncombined presence of the predicational feature, $\mathrm{P}$; that for leave includes also the referential feature $\mathrm{N}$, in recognition of its denotational capacity. But in this combination, $\mathrm{P}$, to the left of the ",", is preponderant. In the categorial representation for a noun, $\mathrm{N}$ preponderates over $\mathrm{P}$, as $\{\mathrm{N} ; \mathrm{P}\}$; while simplex uncombined $\{\mathrm{N}\}$ is manifested as a determiner. $\{\mathrm{P}\}$ and $\{\mathrm{P} ; \mathrm{N}\}$ are simplex categorizations, though differing in being simple vs. combined. Let us approach further investigation of the notion of absorption, and then incorporation, via a consideration of the two simplex categorizations in the sequence may leave and the relation between them. In this way we can begin to determine what such phrasal structures share with complex lexical structures and what is different.

\section{Absorption and incorporation}

The sequence may leave involves the subconfiguration of (1):

1)

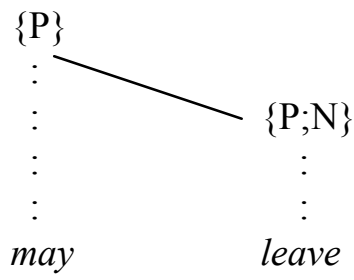

Here the categorizations are associated by the discontinuous lines with (an abbreviation for) the rest of the content of each sign, and the categories are linked by a dependency arc specifying that the category of leave depends on the category of may as its head. As head, the latter component of the expression prescribes the syntax of the construction. In this case it functions as the core of a potentially independent sentence.

In terms of absorption we have the lexical relationship in (2): 
2)<smiles>CC(C)[N+]#[W]</smiles>

Again the categorization for the lexical verb depends on that for finiteness, so that the sign has the syntax of a finite. However, this dependency is not a syntactic relationship, but the dependency holds within a single minimal sign: the two categories thus do not differ in sequence. We have subjunction of $\{\mathrm{P} ; \mathrm{N}\}$ to $\{\mathrm{P}\}$ rather than adjunction as in (1). The presence of the governing $\{\mathrm{P}\}$ is revealed by the syntax and by the presence of different inflectional distinctions, involving secondary categories such as person/number and tense vs. aspect or voice. The absorption of $\{\mathrm{P}\}$ by $\{\mathrm{P} ; \mathrm{N}\}$ does not change the basic realization of the latter, dependent category: the base of the complex form is the same as the categorization and form in (1).

In contrast, incorporation involves a base whose categorization has subjoined to it another category, rather than vice versa. This is what is associated with the form left in has left. The verb form is associated with a $\{\mathrm{P} ; \mathrm{N}\}$ sign that has incorporated a tensed locative, as roughly represented in (3):

3)

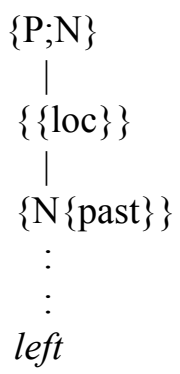

$\{\mathrm{N}\}$ is a pronominal category, seen here as a kind of determiner, with secondary feature $\{$ past $\}$, and $\{l o c\}$ is a secondary feature of the functor category, a category that may occur independently as an adposition. As we have seen, these secondary categories are associated with particular primary categories, and rather than determining basic distribution (as do the primary categories) they merely "fine-tune" the distribution and/or may be signalled morphologically. The functor category, as indicated in (3), is represented by the null combination of primary features. In (3) the pronoun has been absorbed into the functor, which in turn is incorporated into the verb. But overall (3) represents an incorporation: the base in the complex is the superordinate category, the verb; and it 
determines the basic realization of the complex sign, and its syntax. The presence of the incorporated configuration is directly reflected in the inflectional morphology.

The presence of the incorporation blocks the absorption redundancy that permits configurations like that in (2). This redundancy, finiteness formation, might be formulated as in (4), where the ' $\Leftrightarrow$ ' symbol indicates that $\{\mathrm{P} ; \mathrm{N}\}$ may characterize an independent sign, but also can occur in the subjunction relation on the right, as a dependent base:

4)

finiteness formation

$$
\begin{array}{cc} 
& \{\mathrm{P}\} \\
\mid \mathrm{P} ; \mathrm{N}\} & \Leftrightarrow \quad\{\mathrm{P} ; \mathrm{N}\}
\end{array}
$$

Both signs have an entry in the lexicon. The incorporation redundancy associated with (3) takes the form in (5), perfect incorporation, where the head of the resultant configuration is the base:

5)

perfect incorporation

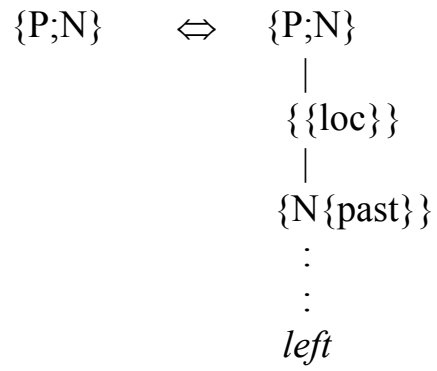

The two redundancies are mutually exclusive. The configuration in (6) is blocked:

6)

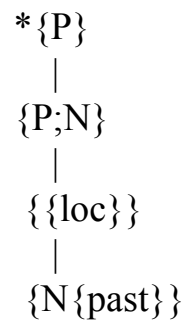


Finiteness is not available to perfect verb forms in English. And the other nonfinite forms are also associated with such a blocking capacity, of course. Finites can be tensed - i.e. they also can incorporate a temporal locative. So that both $I$ was leaving and I left are past, but the two kinds of past cannot be combined in a single sign. In syntactic expressions like I had left, the two pasts are associated with different minimal signs.

An important characteristic of the finiteness absorption that we have looked at is that it is valency-respecting. A finiteness element such as may and have/has/had normally requires to be complemented by a lexical verb. We can acknowledge this as in (7), which includes a representation of this property in the form of the "/" notation.

7)

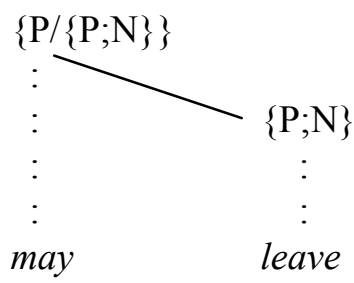

The " " introduces the normal complementation of $\{\mathrm{P}\}$. Similarly, we can represent has left as in (8), where 'perfect' abbreviates the incorporated structure:

8)

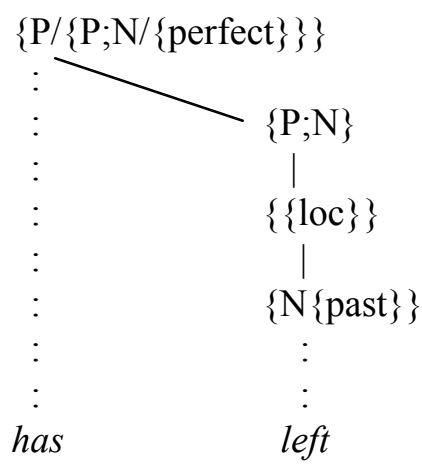

The subjunction of $\{\mathrm{P} ; \mathrm{N}\}$ to $\{\mathrm{P}\}$ in (2) obeys the basic valency of $\{\mathrm{P}\}$ : " $/\{\mathrm{P} ; \mathrm{N}\}$ ". So it might be expanded as in $(9\}$ :

9)

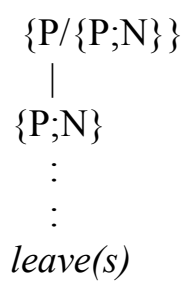


However, in (7) and (9) the valency is redundant. Only the perfect configuration in (8) is contrastive: it distinguishes the syntax of auxiliary have from that of just any finite element.

The absorption in (9) respects the valency of the head. But the incorporation in (5), also might be said to "respect valency", in so far as verbs normally take functors as complements, and among them locatives. So we have, for example, It happened in the past, as represented in (10), where I have ignored the internal structure of the past/Rochester:

10)

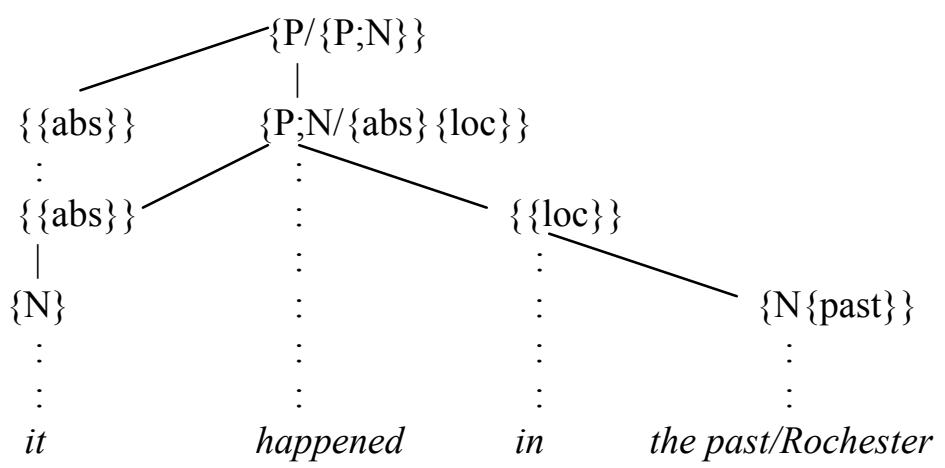

Happen is represented as having the valency of an absolutive (or neutral) functor and a locative. The syntactic functor fulfilling the former specification shares its complement $\{\mathrm{N}\}$ - the normal valency for functors - with the default absolutive of the $\{\mathrm{P}\}$. An absolutive is introduced in predications where it is not part of the valency of the predicator (Anderson 1997: §3.3, 2006: §11.2.1). This absolutive of $\{\mathrm{P}\}$ and its associated subcategorized-for functor precede their syntactic heads, unlike the other complement of $\{\mathrm{P} ; \mathrm{N}\}$, which represents the unmarked case in English. And these absolutives are realized as the pronoun it. Subject formation in (10) is characterized by this sharing between the default functor of $\{\mathrm{P}\}$ and the functor dependent on $\{\mathrm{P} ; \mathrm{N}\}$ that is highest on a hierarchy for subject-selection (e.g. Anderson 1997: $\S 3.3,2006$ : $\S \S 3.1 .3,6.3$ ). What is important here, however, is the observation that happen is a verb that takes a locative functor as part of its valency and this locative may be temporal.

However, the locative in (3) and (8) does not correspond in this way to the valency of leave, which is a directional verb, not a simple locative; semantically it selects locative goal and source (as in They left for Chios from Lesvos, though either or both may not be expressed. A locative is a possible modifier of leave, as in He had left on Tuesday, however: a circumstantial (adjunct) rather than a core participant. We can indicate this by expanding (8) as shown in (11), where I have left the directional valency of the verb unspecified (as irrelevant here), as well as default valencies, such as for determiner in the case of functor: 
11)

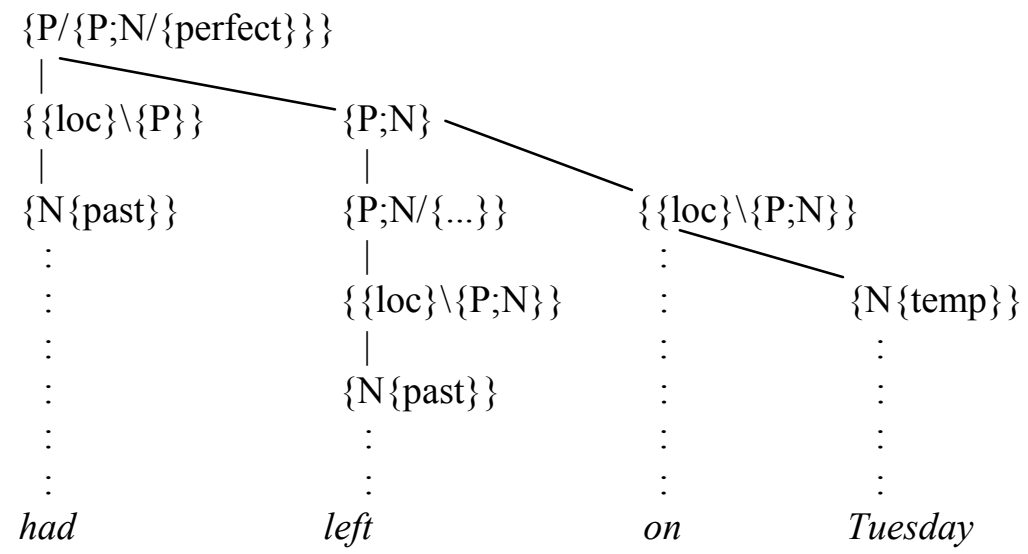

I have not indicated the referential relations between the tensed (and tensible $\{$ temp(oral) $\})\{\mathrm{N}\}$ s. \{past $\}$ presupposes temporal. What I have specified in (11) is that the locative phrase on Tuesday is a circumstantial modifier of the verb, indicated by the le " $\{\mathrm{P} ; \mathrm{N}\}$ " specification of the locative. As a syntactic consequence of this lexical specification, there is a replica $\{\mathrm{P} ; \mathrm{N}\}$ introduced above the basic verb, a replica on which the modifier is dependent, created a larger verb-headed phrase.

There is an "upward" requirement, from modifier to a category of a particular type, here $\{\mathrm{P} ; \mathrm{N}\}$, instead of the "downward" requirement associated with complementation. In this case, valency can be said to be respected in a rather different way: the modified category satisfies the requirement of the locative to be a modifier of that category. As well as satisfying the valency of a verb, a locative can require a verb to satisfy its need to modify. Other locatives (sentence-modifiers) modify $\{\mathrm{P}\}$, as in In fact, he had left on Tuesday. We can thus have "upward" as well as "downward" valency.

But also the incorporated tense locative of left is marked as a modifier of $\{\mathrm{P} ; \mathrm{N}\}$, just as the incorporated tensed locative of $h a d$ is a modifier of $\{\mathrm{P}\}$. In this circumstance there is no syntactic consequence: the modification is internal to the sign. In the absence of a locative phrase such as on Tuesday there is no replica $\{\mathrm{P} ; \mathrm{N}\}$. The main point here, however, is that (11) illustrates that the configuration headed by $\{\mathrm{P} ; \mathrm{N}\}$ obeys the valencies of its component elements in this wide sense of valency that envisages both "upward" and "downward" implementation of colligational requirements.

The complex categorizations we have been looking at involve absorbed or incorporated elements that are functional categories. $\{\mathrm{P}\}\{\}$, and $\{\mathrm{N}\}$ are all functional categories; as such they involve simplex combinations of the features $\mathrm{P}$ and $\mathrm{N}$, including the null combination. Contentive categories, like verb, $\{\mathrm{P} ; \mathrm{N}\}$, and noun, $\{\mathrm{N} ; \mathrm{P}\}$, have complex, asymmetrical combinations, and their 
membership is extensive - indeed, indefinitely extensible. The membership of functional categories is more restricted and slower to change. They are thus less highly differentiated in sense than nouns, and they are necessarily complemented - despite what seems to be the case in such representations as (11), with uncomplemented $\{\mathrm{N}\}$ s. Such representations are incomplete.

The base in both absorption and incorporation is what I have called the "contentive category", to avoid the ambiguity of the term "lexical category". With both these lexical relations, i.e. absorption and incorporation, the presence of a complex categorization that includes a functional category is signalled by its syntax and by the possible presence or absence of inflectional morphology, as in (3) and (4). But only in absorption is there a difference of category for the contentive base: the base of finite left/leave(s) has a different head categorization from in its independent manifestation. In incorporations the base has the same category as without incorporation. Absorptions are thus derivational relations expressed in the lexicon, specifically, in the present case of finiteness formation, a conversion (so-called "zero-derivations"). There is no affixation or internal modification dedicated to signalling the category-changing relationship in this instance. Absorptions that involve more than one contentive category introduce some further factors, however.

\section{Contentive absorptions}

We also find absorption involving two contentive categories, but in English not apparently incorporations of contentives. Because of this and other differences, it is useful to distinguish terminologically between the type of complex categorizations that we have been looking at and those that follow. In the preceding at most only one contentive category is involved in the particular absorption, and in such cases it is the base. And we shall indeed be looking at totally functional absorptions below - anticipated indeed in the tense configurations that undergo incorporation in (1). I shall refer to these as a whole as functional absorptions. Those which follow, which involve a couple of contentive categories (whatever else) I shall call contentive absorptions. It is now the turn of the latter to demand our attention.

As an example, it is semantically and lexically appropriate to describe the verb pot in pot the begonias as involving absorption of the corresponding noun. And here too valency is respected. But since verbs take nouns as an argument only via functors, the valency is rather more extended. The verb pot involves a noun in a locative relation to it, specifically a goal; the noun has absorbed this functor. Thus, we might represent pot the begonias as in (12), where irrelevant parts of the representations are omitted - including the agentive (subject) argument of the verb: 
12)

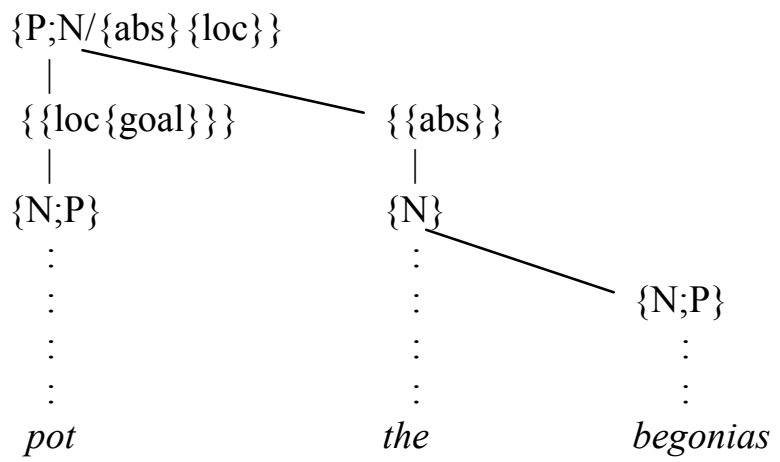

Normally a $\{\mathrm{N}\}$ intervenes between a noun and a functor, as in the begonias. But I have not included a $\{\mathrm{N}\}$ in the subjunction in (12) realized as pot, since the nominal is not referential (cf. e.g. Anderson 2011c: ch.6). Again we have a change of category for the base pot - a conversion mediated by a functor. Notice too that the structure above the exemplifies once more the other kind of functional absorption, involving two functional categories, and again a conversion - from $\{\mathrm{N}\}$ to \{\} .

There is respect for valency in denominal complex categorization (12). However, "valency" in such cases must again be understood to include circumstantial (adjunct) arguments as well as participants (complements including subjects), as here. This further possibility is illustrated by bicycle in bicycle to the office, where the relation of the base is instrumental ('by means of'). Here the base is not in a relation demanded by the verb, but merely compatible with it, as shown in (13), where I have represented the instrumental as an abstract path (a locative that is both source and goal):

13)

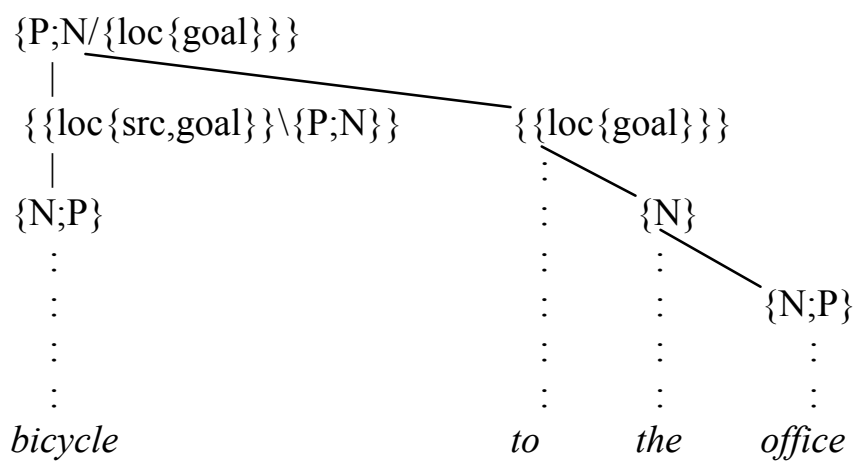

(Again the agentive subject is omitted.) Another thing that is, incidentally, illustrated here is presence of independent functor and determiner, to compare with the absolutive with subjoined determiner in (12). 
Among conversions of this character, Colman - Anderson (2004) label such denominals as that in butcher the animals/villagers as "agent-based", but they seem rather to be based on the verb plus another circumstantial, namely one of manner ("in the manner of"), though in this case involving an agentive noun ("in the manner of a particular kind of agent"). Here too we have a circumstantial base rather than a participant. So much for verbs converted from nouns.

There are also deverbal nouns that might be said to be "valency-respecting", but in an even more indirect way. Consider, for example, cook the noun, with verbal base. A cook is someone who figures (possibly regularly, or even professionally) as an agent with respect to the action of cooking; and agentive is an element of the valency of cook. How are we to characterize this? (14) is a suggestion:

14)

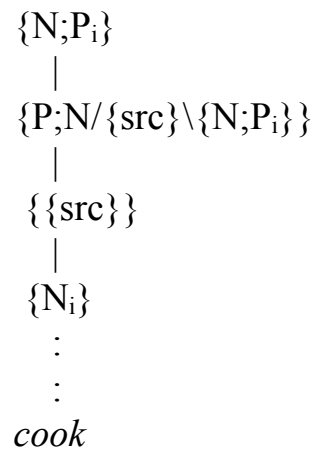

The verb has to have incorporated its agentive - source of the action - argument, in order to serve as the base for the agentive noun. The noun is marked (not as properly referential but merely) as co-referential with this agentive argument.

Such an incorporation into a verb is also what characterizes the passive participle, so that we might represent was dismissed as in (15), where, as with "perfect" in the valency of $\{P\}$ in (8) and (11), "passive" abbreviates the incorporated structure:

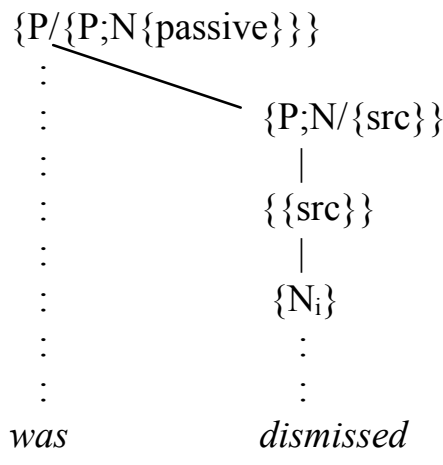


But here, instead of being a component in an overall conversion, the incorporated agentive is (potentially) coreferential with an optional circumstantial, such as that in was dismissed (by the board).

However, to re-focus on (14), it is also important to observe that there is no simple valency-respecting relation between the $\{\mathrm{N} ; \mathrm{P}\}$ and the $\{\mathrm{P} ; \mathrm{N}\}$ that are the core of the conversion: nouns don't take verbs as complements or adjuncts (Anderson 2007: §2.3.3). The two contentive categories in (14) are in an appositional relation: the verb-headed configuration provides an identificatory description of the otherwise minimally contentful noun. And this is mediated by the coreferential link. Compare syntactic hypotactic appositions like the fact (that) the wall collapsed, where the fact is also provided with such a description by means of apposition, and the head of the subordinate clause is coreferential with the head of the determiner phrase. Despite its distinctly appositional status, I have marked the verb in (14) as "upwardly" oriented, like a circumstantial. But appositional status is signalled by the coreferentiality indices. This gives recognition of the appositional link. On such an analysis, (14) involves both a straightforward component of respect of valency and one of appositionality. But there are also lexical conversions that are simply appositional.

What I have in mind are "action" nouns such as walk. In its case we have the simple apposition in (16), with an intransitive agentive verb as base:

16)

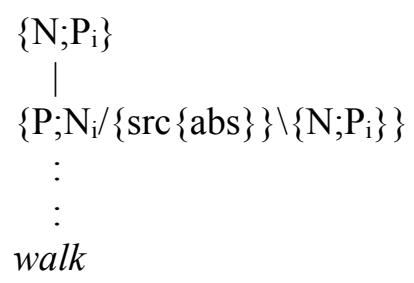

And it seems to be a particular case of a structure associated with the general redundancy that also creates (17):

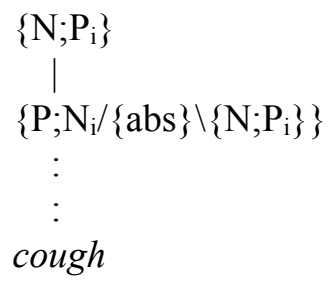

In general, then, the noun simply takes over the verb and its valency to create an event noun. The genitive of John's walk manifests the agentive absolutive that is part of the valency of walk the verb (the agentive argument is interpreted as 
acting on itself - to which I return below), and that in John's cough the absolutive of the verb. The valency will typically include absolutive, the unmarked functor, as in (16) or (17). But even it may be absent in the case of, say, rain: there may be empty ("downward") valencies. Nevertheless, Monday's rain reflects a modifier of the base verb. To this extent, these simple appositional conversions can be said to be valency-reflecting, if not respecting.

"Event" nouns can be interpreted as including a non-prototypical subcategory of state nouns based on stative rather than dynamic verbs. They are exemplified by the converted noun in Rita's love of cats, where the genitive corresponds to the "experiencer" - $\{\operatorname{src}\{l o c\}\}$ - of the related verb of emotion. Compare Rita loves cats: like an agentive, a simple \{src\}, Rita here represents the source of the "scene", but the "scene" is internal, mental, located in Rita, rather than external, enacted. Simple locative stative verbs - contain, include, occupy - seem not to convert to nouns.

We should observe here, to revert to conversions of non-statives, that there are walk nouns based on an absorption of the verb that combines with apposition full respect for valency, as in the cook type of (14), but involving a different aspect of "valency". This is illustrated by (18):

18)

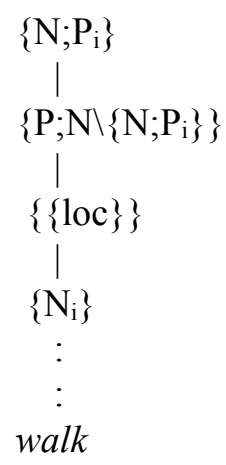

Here the coreference holds with respect to a circumstantial, to denote the location of the walking, as in Along the towpath is my favourite walk. Similar is the manner-based noun of She has a very funny walk.

Given the non-relationality of the prototypical noun alluded to above - they are typically leaves in a syntactic tree - complex nouns always seem to take their base in an appositional relation, simple apposition or in combination with respect for the valency of their base. The valency-rich category verb and the obligatorily valency-bearing functional categories, on the other hand, are associated with valency-respecting lexical relations. We should note finally here that lexical relations of apposition, such as those in (16) and (17) are not as closely matched by syntactic analogues as valency-respecting relations. For instance, in 
the syntax, appositional coreference typically holds between functional categories, as in the fact (that) the wall collapsed; while in (16) and (17) the apposition relates two contentive categories.

The bases for contentive conversion are typically themselves morphologically simple forms or relatively opaque formations, and they often belong to the native or thoroughly assimilated vocabulary. Converted deverbal nouns are also typically count. Let us now compare such conversions with morphologically expressed absorptions.

\section{Derivational morphology and conversion}

We can find parallel lexical relations to those expressed by conversions also signalled by overtly derived forms, manifestations involving the affixation or base-mutation we associate with the core of derivational morphology: such particular absorption-types as we have observed are also manifested in this domain. Thus, instead of the pot the begonias of (12), we could have, with the same relevant lexical structure, embark the passengers. And corresponding to the converted noun cook we have the morphologically derived form baker. Thus the representation in (14) is equally appropriate to it. Cooker (in the appliance sense), however, includes an instrumental, so circumstantial, relation, rather than an agentive participant, in its categorization. These last illustrate that affixation can also display something of the ambivalence of converted forms, despite the possibilities for differential expression.

In terms of appositional absorption of a noun, the walk of (16) is roughly paralleled by perambulation, and the cough of (17) by expectoration - though there are lots of more everyday examples, often with more transparent morphologies. The conversions of "experiencer" verbs like love are paralleled by (admittedly obsolete) morphological formations like hatred, as well as the very productive -ing suffix.

The -ion suffix of perambulation and the others are associated with the " $\left.\left\{\mathrm{N} ; \mathrm{P}_{\mathrm{i}}\right\}\right\}$ " specification in their categorization, parallel to that in (17). It is this specification that requires the change of category. But the suffix is not the head of the morphological construction, but realizes the part of the categorization of the verbal component of the derived complex that correlates with the introduction of the noun categorization. The same is true of the -er suffix of baker (or cooker) and the em- prefix of embark. Affixes are not and do not represent primary syntactic categories but reflect the morphological mechanism triggered by the specification of the base that initiates absorption.

Further distinctions in type of category change are also shared between conversions and overt derivational morphology. Consider the complex structure associated with result nouns, compared with the simple event noun. We can 
represent the event noun invention in the same way as walk and cough in (16) and (17), except that, as well as introducing an appositional subjunction relation, the redundancy is marked by a suffix, i.e. as in (19a), where again, by general convention, the verbal categorization simply carries over its valency, and therefore need not be expressed in such formulations:

19) a. $\left\{\mathrm{N} ; \mathrm{P}_{\mathrm{i}}\right\}$

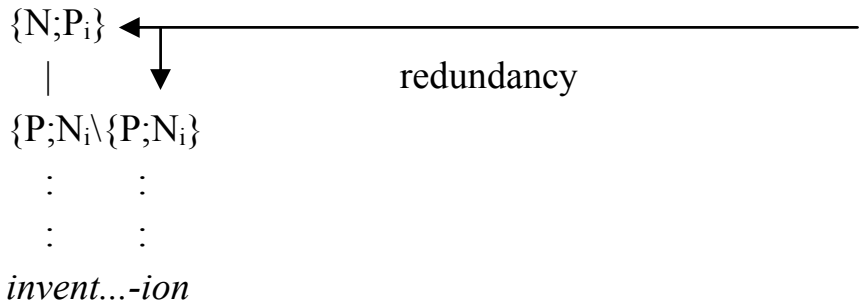

b.

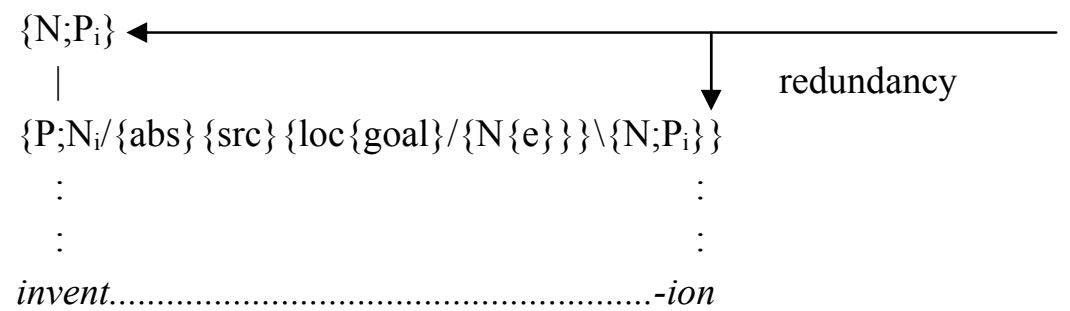

The arrows point to the elements introduced by the lexical redundancy that expresses the absorption, and the horizontal dotted line reminds us that the ordering of the elements is determined in the morphology. This noun, which underlies the most obvious interpretation of a chance invention, contrasts with the corresponding concrete result noun in an exhibition of inventions.

The representation of the latter noun given in (20) contains both apposition and respect for valency:

20)

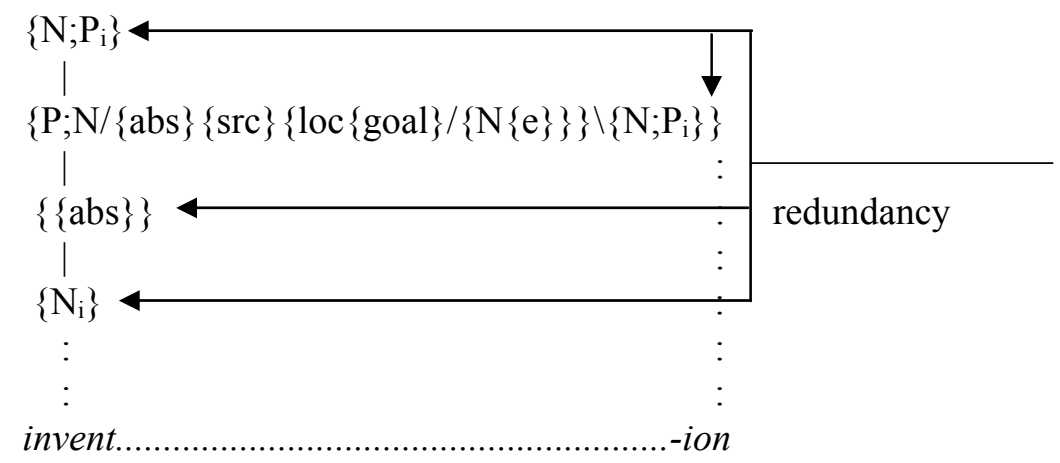


(20) thus involves a more complex redundancy. However, we must also recognize that the base verb itself has complexities not acknowledged in (19a) that are relevant to an understanding of the derivatives. The " $\{\mathrm{loc} /\{\mathrm{N}\{\mathrm{e}\}\}\}$ " in the representation of the base in (20) is present in both the event and the result noun, as show for the latter in (19b): it denotes the special kind of location that we call "existence": an "invention" comes into existence in some domain, either what is perceived as the concrete world, or the world of the mind, in so far as these can be distinguished. Hence in (20) and (19b) the locative is a goal; "existence", interpreted as being located in a world, is the goal.

The effective event denoted in these cases is a bringing into existence of an entity, concrete or abstract; the result is that entity. The incorporated absolutive is coindexed with the derived noun. Such an incorporation may be what Malicka-Kleparska intends by "incorporation of the most object-like thematic role of the verb" (1988). The of-phrase in Bill's invention (of the puzzle) is in apposition with the incorporated absolutive under the event interpretation of (19), and is absent with the result interpretation of (20). The genitive in that phrase realizes a source in apposition with the incorporated source of the base of invention (not indicated in (19) and (20), in the interest of graphic simplicity.

There is a similar distinction to that associated with the two invention's between the noun find of a lucky find - event noun - and that of an exhibition of the finds - result noun. These are again based on an existential structure of some sort, such that derivational relation discover/discovery is a closer analogue. But the two find's both involve conversion from the verb, of course, rather than morphological derivation, as in (19) and (20) and discovery. Similarly in both conversions and morphological derivations of nouns we can find that the verbal distinction between progressive and non-progressive may be preserved, though covertly. Thus, a progressive interpretation is attributed to both my walk and the distribution of the bread in the context of ...was interrupted, an interpretation lacking in the context ...was on Tuesday. Both valencies and secondary features of base verbs may be relevant to the realization or interpretation of deverbal nouns.

The unmarked event noun is non-count, but count readings are often possible, as in her successive discoveries of flaws. Result nouns are one variety of incorporation of a coindexed argument by the base verb. Nouns formed on the basis of such absolutive-incorporations in general are frequently count nouns, as with collections; but they may be non-count, as with non-event, concrete condensation, for instance.

\section{Derivational morphology or conversion?}

Thus far in our discussion, the distinction between conversion and overt morphological derivation seems to be clear cut, formally. But there are circum- 
stances in which there might appear to be an ambivalence. This arises particularly in languages which have paradigm classes - declensions and/or conjugations. Often, we can associate such a class with the formation of a particular stem differentiated from the root by affixation or by mutation of the root itself. The weak conjugations of Old English offer an example, and introduce the apparent ambivalence.

The formation is reasonably transparent in the case of class II weak verbs, such as ginian 'yawn' or prōwian 'suffer' (where I have included the conventional editorial length mark). In these infinitive forms we can isolate a recurring putative stem-forming element spelled $-i-$, which also appears as such in some other parts of the paradigm. But the exponence of stem formation is not constant. Elsewhere in the paradigm we find the spellings $-o$ - and $-a$-instead: compare past tense prōwode 'suffered', first or third person indicative singular or subjunctive singular, and present third person singular prōwap 'suffers'. However, this does not obscure the status of the stem-formative as such; it is merely that its morphophonological exponence, and so spelling, is systematically diversified, in response to whatever inflectional categories are also being expressed in the particular form. We have contextual diversification, creating sub-stems.

In class I of the weak verbs, however, we find that the pre-historical stemforming $[-\mathrm{i} / \mathrm{j}-]$ we still find in herian 'praise', with a "light" root and a coda $[\mathrm{r}]$, has been lost in many circumstances. And it leaves only an indirect trace in the shape of gemination of the root-final consonant - as in cnyssan 'strike, shake' together with the presence of a vowel which belongs to the set resulting diachronically from $i$-mutation (and earlier effects of $[-\mathrm{i} / \mathrm{j}-]$ ) - as again in cnyssan or it is reflected simply by $i$-mutation - as in the "heavy" root hieran 'hear', where there is no gemination following the long vowel. Only "light" roots ending in $r$ retain a stem-forming $-i--$ as was illustrated by herian 'praise'. In the second and third person singular present indicative of "light" roots and in their past, gemination and the ri of herian etc. are "replaced by" a single consonant plus a vowel spelled $e$ : cnysest/cnyseb and herest/herep. Compare "heavy" hierst/hierp, where there are no manifestations of stem formation (barring the results of $i$-mutation).

This is brought together in Table 1 .

Table 1. Old English Weak Verb Stems

\begin{tabular}{l|l|l|l}
\hline & Infinitive & 3rd sing. Pres. Ind. & Past Pl. Ind. \\
\hline Class I & cnyssan 'strike' & cnys(e)p & cnysedon \\
& herian 'praise' & herep & heredon \\
Class II & hieran 'hear' & hierp & hierdon \\
& ginian 'yawn' & ginap & ginodon \\
& prōwian 'ask' & prōwap & prōwodon \\
\hline
\end{tabular}


This highlights the absence of any sign of stem formation with the "heavy" roots of class I, except for the result of $i$-mutation. And this is often the case even with the second and third person singular present indicative of verbs like cnyssan, as is indicated by the parenthesis. But even with class I it is legitimate to talk of stem-formation, even though the stem is not necessarily expounded by a distinct formative: the exponence of each inflection is added to or is coexpressed with a particular stem form - a form characterized at the minimum by presence of $i$-mutation. Stem formation contrasts in this respect with that associated with class II.

So much for stem formation in the Old English weak verbs. What is of interest here is the status of stem-formation, and more generally, paradigm classes differentiation among which may or may not involve stem-formation. Are these always purely morphophonological? If this is the case, they would simply subclassify the members of a particular part of speech in terms of the means of expression of the subcategories (such as tense, or number) associated with that part of speech. Or can choice of class have a derivational role, particularly, say, in the case of the weak conjugations of Old English? Before confronting these questions, let us look at the other major class of verbs in Old English, the strong verbs.

Each of the strong conjugations deploys a series of stems signalled by modification of the root vowel - ablaut - as well as secondarily by $i$-mutation in certain circumstances (not illustrated here). Again this correlates with the presence of particular inflections. This is exemplified in (21) by the left-to-right series of forms from members of strong classes III and IV:

21) infinitive non- $2^{\text {nd }}$ sing. past ind. past pl. ind. past part.

\begin{tabular}{|c|c|}
\hline $\begin{array}{l}\text { helpan 'help' } \\
\text { beran 'bear' }\end{array}$ & $\begin{array}{l}\text { healp } \\
\text { beer }\end{array}$ \\
\hline
\end{tabular}

Anderson (1970) suggests that the quality of the root vowel in the strong verbs is non-contrastive, and is assigned by stem-formation, which involves amplification of the root vowel with different vowel qualities depending on the inflectional categories being expressed, and with class differences, such as are illustrated by (21), depending on the phonological structure of the root. I introduce this brief allusion to the strong verb since it will have some significance in what follows, and not just because in this case stem formation lacks an obvious derivational role. But our concern here is primarily with the weak verbs.

It looks as if stem formation with weak verbs is primarily a property of inflectional morphophonology: it determines the character of the paradigm members. And this seems also to be true of the distinction between class I and class 
II. However, some members of the weak verb classes are patently derived, and often bear some kind of causative sense. Consider, for example, from class I, trymman 'strengthen' and mêtan 'meet' with trum 'strong' and mōt 'meeting'. And with respect to class II lofian vs. lof 'praise', respectively verb and noun, and $c l \bar{x} n s i a n$ vs. $c l \bar{x} n e$ 'clean', respectively verb and adjective. (For an extensive listing, with both noun, adjective, and verb bases, see Lass 1993a: 29-31.) Are, then, these exponents of stem formation derivational affixes/mutations?

It is true that there are many such verbs that lack an obvious synchronic base (for examples see Lass 1993a: 32). But our corpus of Old English is rather limited, and moreover such gaps are not unfamiliar from study of the particularly fossilized derivational morphology of present-day languages. We also find what Lass calls "co-derivations", specifically pairs where the noun or adjective is clearly derived - and marked by -ung or -ig, for instance, and the verb is a weak verb whose root may indeed in some cases also be the base of the non-verbal form. That is, the related verbal and the non-verbal items share a root, as a common base. These are exemplified by blētsung consecration' vs. blētsian 'bless', and cwānig 'sorrowful' vs. cwänian 'lament'. All this seems to be consistent with the weak stem formatives being fossilized markers of derived verbs, specifically causatives.

However, not all the derivational relations involved seem to be obviously causative: take, for instance, from class II, polian 'suffer', which seems to be based on the same item that we find in the compound adjective pole-mōd 'of patient disposition'; consider too lufian vs. lufu 'love', respectively verb and noun. But again such exceptions, or rather alternative formations, are common in (established) derivational morphology: witness present-day comfortable compared with movable, singable, washable, electable, etc. Nevertheless, a more conservative view of the Old English weak verb would be that the stem formations mark simply absorption of verbality, which may in particular instances involve a variety of notional distinctions - with, certainly, causative and inchoative being prominent among them. But there are other considerations to take into account

Examination of the status of these stem formatives seems to me to be opening up an area somewhere between overt derivational morphology and conversion. Let us firstly re-consider the above phenomena in relation to the former. These stem formations would be rather unusual derivational markers, given their partly idiosyncratic variation in manifestation, and participation of this manifestation in the expression of inflectional morphology. In Kastovsky's words, they have "merged with the final inflectional endings or with the preceding base" (1993: 78). But their presence is transparent in the majority of cases, provided we allow for two-way multiple exponence as a means of specifying precisely what is signalled by the components of a form. 
In order to clarify what I understand by such exponence relations, the category-to-exponent relationships for three sample weak verbs are presented in (22), for a class II verb form, and (23), for class I:

22)

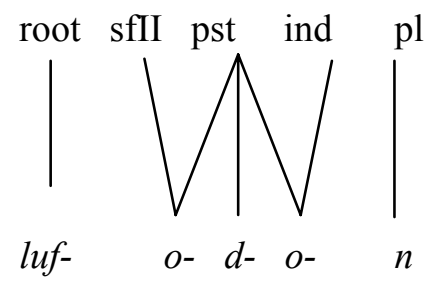

a.

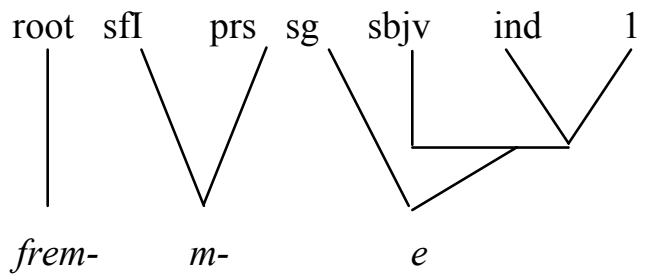

b.

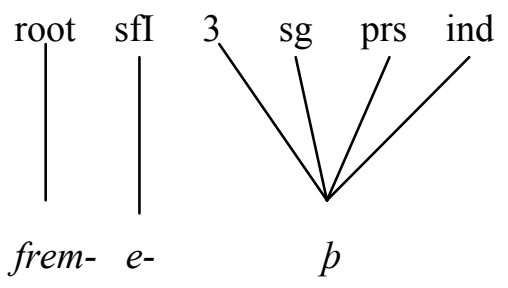

(here $\mathrm{SF}=$ stem formative ( + class number), $\mathrm{PST}-$ past, $\mathrm{IND}=$ indicative, $\mathrm{PL}=$ plural, $\mathrm{PRS}=$ present, $\mathrm{SG}=$ singular, $\mathrm{SBJV}=$ subjunctive, $1=$ first person, $3=$ third person). Upward splits indicate an exponent of more than one category, downward splits indicate multiple exponence of a category, and the horizontal that links subjunctive and first person indicative in (23a) presents alternative categorizations ("syncretism"). I have not attempted to characterize the synchronic role of $i$-mutation (see, however, Anderson 1998, 2011b: §2.3). It is perhaps significant that in this paradigm the stem-forming vowel that can be left out, that in (23b), is where it is not combined in exponence with an inflectional category.

Lass (1993a,b) and Kastovsky (1993) contribute to a debate initiated by Dalton-Puffer (1992) that the first of these (Lass 1993a) entitles "Old English -ian: Inflectional or derivational?". The representations in (22)-(23) imply that this is an unfortunate way to formulate what is at issue here: -ian is not a unit, any more than is -od-in (22). Dalton-Puffer (1993: 42), picking up a point made by 
Ritt (1993), comes closer to an appropriate decomposition when she observes that "once the verbs are not in the infinitive, -ian is gone, too, and other grammatical morphemes indicating person, number and/or tense step into its place". But the debate awaits Colman (1996: §4) for clarification of the status of the sequence -ian. Weak verbs are composed of a root, a stem former of some sort and the paradigm associated with weak stems, and -an is just part of this last. The interesting question is: does the stem forming element in weak verbs function derivationally. I am going to suggest that in historical Old English it doesn't, and that weak verbs that show absorption are converted (not derived morphologically) from other word classes.

However, the change in grammatical status associated with weak verb formation is signalled not just by the syntax of the form, and possibly the presence of certain secondary categories (e.g. tense, person), as in simple conversion, but it is also reflected by the choice of a particular paradigm class. So that, we might represent a de-adjectival or denominal weak verb, schematically, as in (24), where ' $W K$ ' is an abbreviation for the morphophonological characteristics of the class (conflating for present purposes the sub-classes):

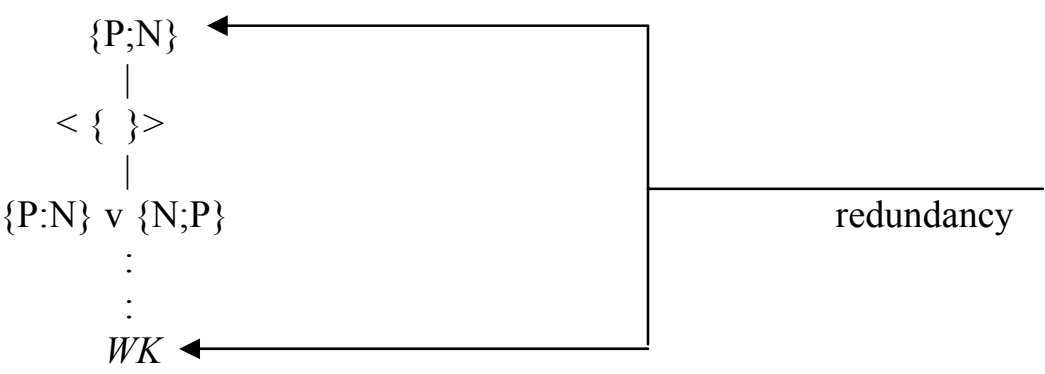

The optional unspecified relation (within the angles) for the base adjective/noun is to allow for a variety of formations. But then, given this variety, need we say more than that generalization applying to the cases we've been looking at is that have been converted to verbs (with individual conversions showing idiosyncratic variation)? But, then, isn't the choice of weak class part of the derivation? However, I shall argue that these derived verbs have merely adopted the most obvious conjugation - for reasons we shall now come to.

Say that these stem formers are just that, synchronically, and that the members of the above pairings of weak verbs and their bases are related by simple conversion, after all. The weak conjugation is simply the conjugation that any converted bases adopt. And the reason for this is fairly obvious. Any strong verbs converted from another part of speech would involve some uncertainty, or at least derivation via a variety of vowel-mutations, depending on the vowel of the base. Only archaic formations exemplify derivational ablaut relations in Old 
English. Such is illustrated by the pair beran 'bear' vs. bora 'bearer' - where, indeed it is the agentive noun that seems to have absorbed the verb root - or rather stem, that of the past participle in -o-. Given the non-productivity of ablaut-based derivational relations, and the opacity that would be involved in relating a non-verbal base to a strong-verb paradigm, the strong verb is not a suitable derivational target in pre- and historical Old English. Much the easiest option for absorption of a verb is via conversion to the weak verb. And this, of course, involves conformity to the stem formations that subtend the paradigm of such verbs. These formations themselves are only indirect indications of an absorption - just like, after all, the presence of person/number and tense on a verb root that only indirectly reflects the absorption of finiteness.

This indirectness is indicated by the dotted line in (25):

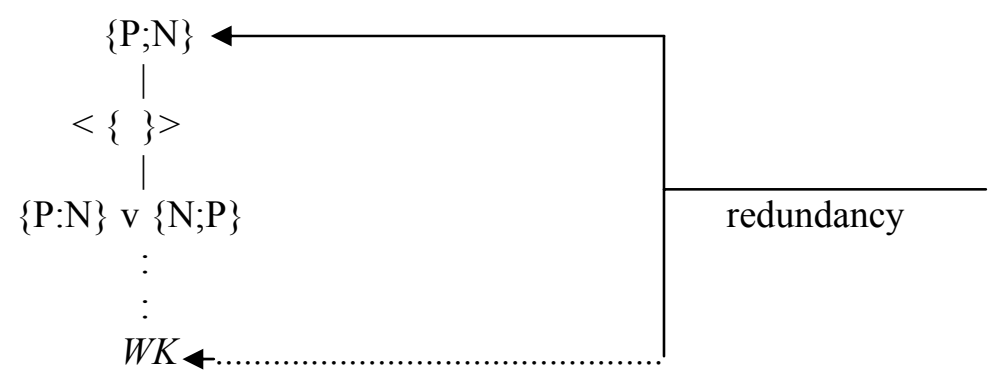

A derived verb in Old English is weak by default; its weakness involves a subsidiary redundancy. Thus, the stem formative does not indicate any derivational information beyond that signalled by other aspects of the inflectional morphology of the class, such as person-number marking.

This is not to deny that at other stages in the history of the language the ancestors or descendants of these stem formations may be most obviously interpreted as derivational markers. Thus, a food/feed relation lingers on as a minor non-productive mutative (i.e. morphological) derivation; though, on the other land, love, verb and noun, involve conversion - most obviously from verb to noun. What I'm suggesting is that a morphologically derivational status for these absorptions and these stem formers does not seem to be appropriate in historical Old English.

On first consideration, any such status is also absent with respect to the Old English noun declensions. Of the strong nouns, the only sign of an earlier stemforming element is the effects of $i$-mutation and gemination in historical jastems and $j \bar{o}$-nouns, and the effects of the of [-i] of $i$-nouns, and the presence of stem final $-u /-w$ in $w a$-stems and $w \bar{o}$-stems. And the $-u$ of these last is absent after "heavy" roots: compare $l \overline{\mathfrak{x}} s$ 'pasture' with sinu 'sinew'. These are nominatives; the accusatives are $l \overline{\mathfrak{x}}$ swe and sinwe. There is also much obscuration of 
stem origins resulting from analogical adoption across declensions. In general, synchronically, we seem to have simply different sets of inflectional paradigms attached directly to the root. So there is no opportunity for a derivational status for a stem formative.

The exponent of stem formation of the weak declension in Indo-European is traditionally reconstructed as being realized as [-en-] (and ablaut variants). And this is reflected in the recurrent -an-inflection of the descendant Old English paradigm (the earlier inflections having disappeared except in the genitive and dative plural). The paradigm for the Old English masculine noun nama 'name' is laid out in table II:

Table 2. Old English Masculine Weak Noun Paradigm

\begin{tabular}{l|c|c}
\hline & singular & plural \\
\hline nominative & nama & naman \\
accusative & naman & naman \\
genitive & naman & namena \\
dative & naman & namum \\
\hline
\end{tabular}

The result of the history is much syncretism - only four distinct forms. There is no motivation here also for recognizing an exponent of stem formation, or even marking by mutation.

Lass (1993a: 31) cites as one of several "fully transparent suffixes" deriving non-verbals from verbs in Old English the "agentive $-a$ ". But there is no motivation for regarding this $-a$ as other than an inflection, part of the paradigm in table II. What we have is conversion. However, it is apparently a conversion that targets the weak declension.

Though, as I have suggested, the weak conjugation is an obvious target, for formal reasons, in conversion to a verb, another question arises in relation to the noun declensions. Can there be notional reasons for selection of a particular declension, given that in all of these declensions there is not the problem that ablaut is paradigmatically relevant, and given the simplifications of their historical post-root structure and the formal convergences among them? That is, say the weak declension is a target for agentive conversions. Sometimes these involve a strong verb base, as with bora 'bearer'. Others manifest "coderivation", as with hunta hunter vs. the verb huntian 'hunt'. So that an analogue to (25) might be appropriate for the noun in this case - say (26), where on notional grounds hunt- is taken to be a verbal base: 
26)

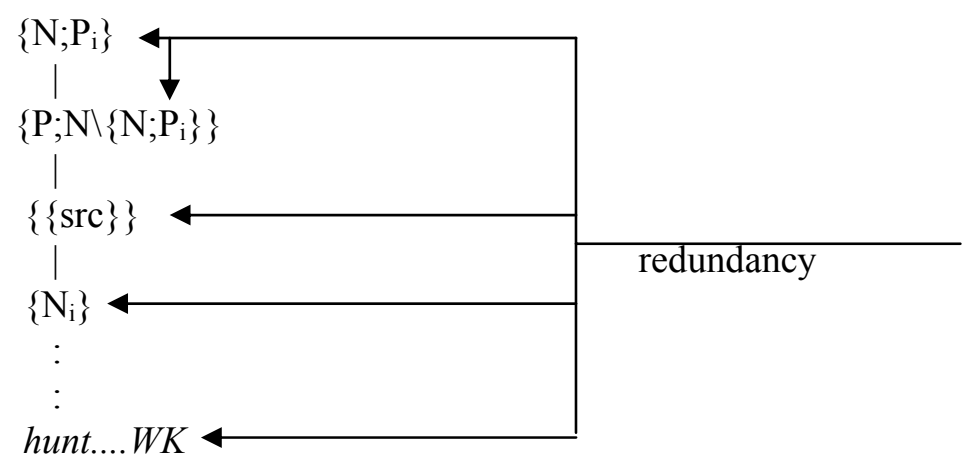

But here the selection of paradigm signals agentivity; and it is not simply a default, as I've suggested in the case of (25). Here we would have an absorption implemented by conversion and positive paradigm selection.

This allows for only a small proportion of the Old English weak nouns, however. Colman (MS) argues for the presence with not just weak nouns but also with weak adjective forms and weakly-inflected names of a much more pervasive property than "agentive" that she labels "identification". That names, for instance, should be attracted into the weak declension (even if etymologically based on a strong noun) is unsurprising in these terms. Such a relationship is exemplified by the noun brord (strong) 'prick, lance' vs. the name Brorda (weak). The main function of names is to identify individuals, so that they can be referred to and addressed. As she concludes, we have a conversion, involving a word-class change that includes acquisition of the notional property of "identification" and that is signalled by choice of declensional class.

Choice of paradigm class may have a derivational role, if what I have said about the Old English weak noun class is appropriate; and even stem-formatives whose synchronic role is simply paradigmatic, as, say, with that of the Old English weak verb, may originate in as contentful markers of derivationality.

\section{Collateral adjectives}

The previous section was concerned with absorptions about which there has been doubt concerning whether they are conversional or overtly derivational. In this section we are moving towards looking at categorially complex structures that are characterized neither by distinct derivational morphology nor by conversion. Nevertheless, the complexes allegedly exhibiting categorial complexity can be associated with the same notional and structural properties as we can identify in the case of the results of such overtly expressed relations. We shall eventually be concerned here, then, with cases of covert categorial complexity. But I approach these in the present section via what might be seen as an inter- 
mediate type of situation, as exhibited in the phenomenon of collateral adjectives. These are "[adjectives that] are closely related in meaning but different in form from their corresponding nouns, like equine and horse ..." (Pyles - Algeo 1970: 129). "Collateral" refers to the Latinate or Greek as opposed to native source of the adjective (but is an unfortunate label, given that the related items may indeed not be historically collateral).

There is a thorough study of these adjectives in English by Koshiishi (2010), along with discussion of many ramifications concerning morphological structure. In their foreword to Koshiishi's work, Giegerich - Pullum (2010: xiii) provide a succinct account of the central argument of the book, as follows: "[s]tandard form-based morphology" allows that:

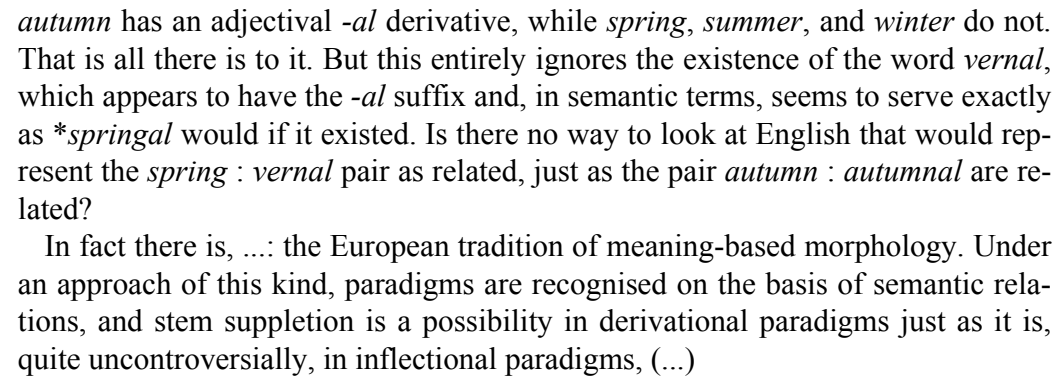

This, it seems to me, is to somewhat underplay the innovative character of what Koshiishi is proposing.

As Koshiishi himself acknowledges (2010: 57), "scholars ... are normally not willing to apply the term 'suppletion' to derivation". And there has been if anything greater to resistance to the attribution of "paradigmaticity" to derivation. Koshiishi goes on to explicate the reluctance to admit "derivational suppletion". He observes that "the concept of suppletion presupposes the existence of neat paradigms, which are typically observed in inflection rather than in derivation" (2010: 57). Nevertheless, he later subscribes (2010: $\$ 2.5)$ to the idea, put forward by various previous scholars, that it is legitimate to talk of "derivational paradigms", and he suggests "my approach can be interpreted as a kind of grammaticalisation of paradigmaticity based on semantic fields" (2010: 67). However, it seems to me that terminology such as "derivational paradigm" does some violence to the traditional, and useful, understanding of paradigmaticity. But I suggest that suppletion is not so closely tied to paradigmaticity that it can't be applied to derivational relations.

Table 2, repeated here for ease of reference, presents a traditional twodimensional paradigm. 
Table 2. Old English Masculine Weak Noun Paradigm

\begin{tabular}{l|c|c}
\hline & singular & plural \\
\hline nominative & nama & naman \\
accusative & naman & naman \\
genitive & naman & namena \\
dative & naman & namum \\
\hline
\end{tabular}

The forms in the slots defined by intersection of the two dimensions are in a paradigmatic relation with each other: they are alternative occupants of the same syntagmatic positions, laying aside restrictions to do with rection and agreement. We recognize this by labelling them all noun forms. The traditional paradigm is in the first instance the grid of the word forms assumed by an exemplary or citation member of a particular morphophonemic class. It then can refer to the set of forms of any member of the class. Definitions such as that offered by Anderson (1992: 134) belong in such a tradition: "an item's paradigm is the complete set of surface word forms that can be projected from the members of its stem set by means of the inflectional Word Formation Rules of the language".

The relation between blètsian 'bless' and blètsung is not paradigmatic: they are forms belonging not just to different morphophonological classes but also to different word classes. They contrast syntagmatically, not paradigmatically. Forms belonging to different word classes are, by definition, syntagmatically distinct, and incapable of forming (part of) a paradigm. In terms of the framework outlined here, derivation involves absorption, which has the effect of changing the category of the head. Even when the absorbed primary category is the same as that of the base, apart from some secondary feature - as in sexism, there is creation of a new word, not of a different form of the same word. Incorporations and secondary categories (such as number or gender) are, on the other hand, what may be manifested in the paradigms of inflectional morphology, paradigms of a constant word class.

What inflectional exponents (affixes, internal modifications) share with the often morphophonologically similar exponents of derivationality is their role, together with the root, in signalling the "séries associatives" discussed by Saussure as co-existing with syntagmatic "coordinations associatives" (1916: 177-8). The former are comprised "des unités qui ont un élément commun avec le syntagme", as illustrated by (27) (Saussure 1916: 178), where the arrow corresponds to "la chaine parlée": 
27)

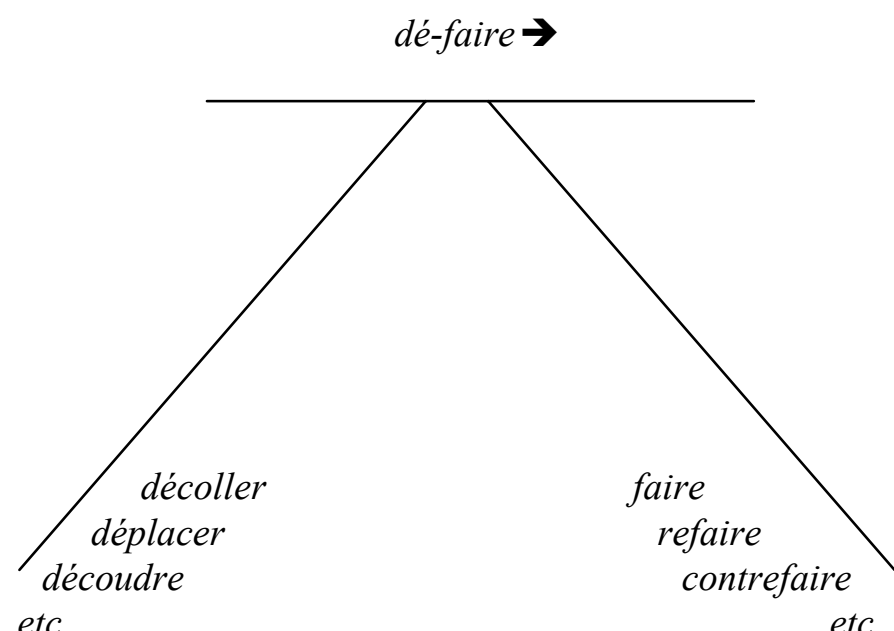

On the left we have a series of bases and to the right a series of derivational prefixes (including a null occurrence).

We can display stems and inflections in the same way:

28)

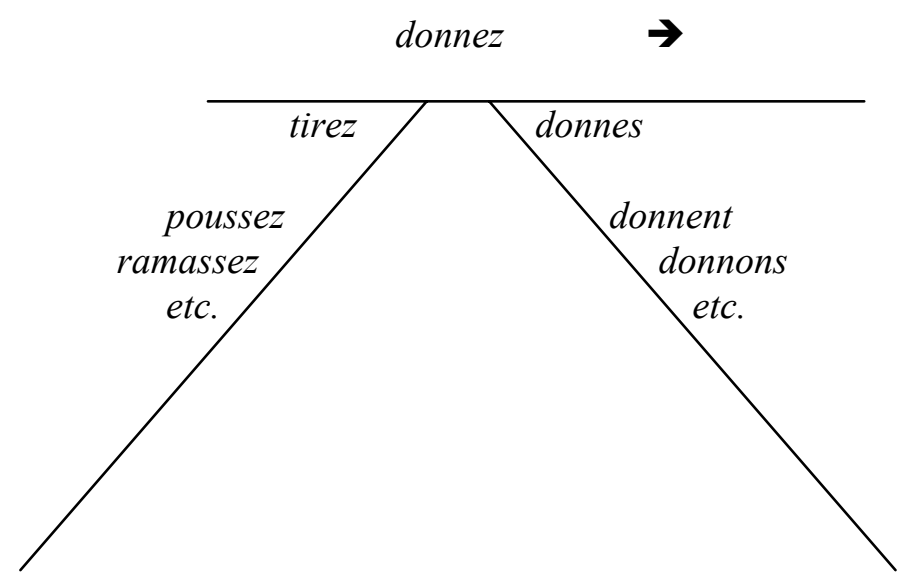

But it is only in this case that a series of forms displays a paradigmatic series, a series of forms of the same word. Not all such associations are paradigmatic. In the present diagrams, only the forms in the right-hand branch of (28) constitute part of a morphological paradigm.

The items in the right-hand branch in (27) might be said to involve a "lexical paradigm". And so might the left-hand branches in both (27) and (28), though 
of a rather different sort. But this terminology doesn't add anything to the notion "associative series", or Matthews' (1974: 155-6) "relationships 'in absentia". In none of these instances do we have anything resembling an "example" or "model" (Greek $\pi \alpha \rho \dot{\alpha} \delta \varepsilon \imath \gamma \mu \alpha)$ of the systematic variation in form to be found in a morphophonological class. The items involved in the right-hand series of (27), in particular, are not part of a morphological paradigm. What unites all the branches in (27) and (28) is their common status as showing associative series, not necessarily traditional paradigmaticity (cf. Anderson 2011a: 23-4). Paradigms consist of sets of word forms, not sets of distinct words, or sets of inflectional or derivational affixes, or of bases or of stems.

Saussure (1916: 173-5) even envisages "rapports associatifs" between morphologically unrelated lexical items, a usage that prompted subsequent structuralists to reject the term "associative" and to misuse (to my mind) the traditional term "paradigmatic" in applying it to all the relations in the preceding paragraphs (see Matthews 2001: 50-1), which all have a morphological basis. Saussure points out, however, that paradigms are composed of very special series which are distinguished by not being composed of an indefinite number of members (1916: 174). As concerns the internal categorization, at least, of simple lexical items, this will be pursued in the following sections.

In all of the examples in (27) and (28) the exponence is crucial in identifying the lexical word and the recategorizations and/or secondary categories involved. What is lacking with collateral adjectives is such identification of the base: the association is purely semantic, except that the presence and the sense of suffixes such as -al and -ine (in vernal, equine etc.) suggest the likely category for the base, as well as for the derived form. To the extent that the inflectional paradigm provides a similar, though stronger, more grammaticalized matrix for a suppletive stem, it is perhaps not inappropriate to talk of suppletion of a base of a derived form as analogous to suppletion of the stem of an inflected form. This does not seem to me to necessitate an appeal to "derivational paradigms", however. And this is, of course, not to deny that well-defined lexical relations between morphologically and exponentially unrelated lexical items can be identified and their categorial structures characterized - as will emerge in what follows this section.

As I observed above, collateral adjectives are an intermediate case between derivationality and such covert expression. Koshiishi (2010:1) defines a collateral adjective as a "Latinate suppletive relational adjective" (where Latinate is intended to include Greek-derived). Relational adjectives are a sub-type of nonpredicative classifying adjectives, specifically "those typically having a meaning 'pertaining to', 'relating to', or 'associated with' and often have a morphologically strong relation with a noun" (Koshiishi 2010: 113). Such are the adjectives in a mathematical genius and musical analysis. In defence of the notion that collateral adjectives are best understood as suppletive instances of the lar- 
ger class of "relational adjectives", Koshiishi (2010: ch.3) shows that they share with (other) relational adjectives a range of semantic and syntactic properties.

It seems indeed that such a suppletive relation is replicated elsewhere in the lexicon of English - though possibly with not the same richness of manifestation as is displayed by the "collateral adjective" phenomenon. There are even cases, such as prey and predator, which are genuinely (etymologically) "collateral" - and where some exponential resemblance remains. Compare the inflectional relation illustrated in bring and brought.

What I turn to now are instances of lexical relations where neither morphological derivation, conversion nor suppletion can be appealed to, but where the item semantically corresponding to a derived or converted item exhibits the distributional properties of such. We are not concerned just with items like expedition that, given their morphology, are apparently derived, and in the case of expedition show arguments normally associated with verbs: Clutterbuck's expedition to the north last year. But there is lacking a straightforward synchronic source for any putative base, even a collateral one. The expedite/expeditious forms are not synchronically relevant in the present case, for instance. However, what the next section also focuses on are forms that are apparently morphologically simple and unconverted, but display the semantic and syntactic complexity that elsewhere correlates with the categorial complexity of morphologically derived or converted forms.

\section{Covert absorptions}

There is evidence for covert absorptions in the form of indications of categorial complexity with non-derived forms of the sort we have associated with derived (including converted) words. Such categorial complexity of apparently simple lexical items is perhaps most obvious with simple nouns that display characteristics analogous to those we have identified as belonging to overtly deverbal nouns. Let us begin by considering nouns that apparently are morphologically derived but lack a source for their base.

The "event" nouns eruption, mischief, and misfortune are, of course, as such, notionally non-prototypical as nouns. The morphological structure of the first of these suggests why: it is based on a $\{\mathrm{P} ; \mathrm{N}\}$ that surfaces independently as the verb erupt. However, a verbal equivalent to the "event" nouns mischief and misfortune is not apparent. In order to confront this, I want to dwell first on the semantic and syntactic role of the "motivated" base of forms like eruption.

It is the presence of a $\{\mathrm{P} ; \mathrm{N}\}$ in the representation of eruption that is the basis for an absorption that introduces the "event" interpretation and allows optional circumstantials that reflect this dynamic property, as with last year's eruption, as well as a participant such as is present in the eruption of Vesuvius or Vesuvius' eruption. Prototypical nouns may be associated with attributives (as in large stone, 
etc.), but not with participants in or circumstantials to a represented event. In Vesuvius erupted, on the other hand, the role assigned to the subject is, as a participant in the event, part of the valency of the verb; and in It erupted last year the location-in-time role is a modifying circumstance-to-the-event that seeks a verbal head. Such are not associated with prototypical simple entity-denoting nouns like pebble. Instead, nouns attract attributives such as yellow or large. It looks as if it is the complex structure of eruption that licenses the verbal arguments.

We can sketch out this complexity of structure, as it is involved in the eruption of Vesuvius and Vesuvius' eruption and last week's eruption, as in (29), where the representations omit irrelevant structural information:

29) a. $\{\mathrm{N}\}$

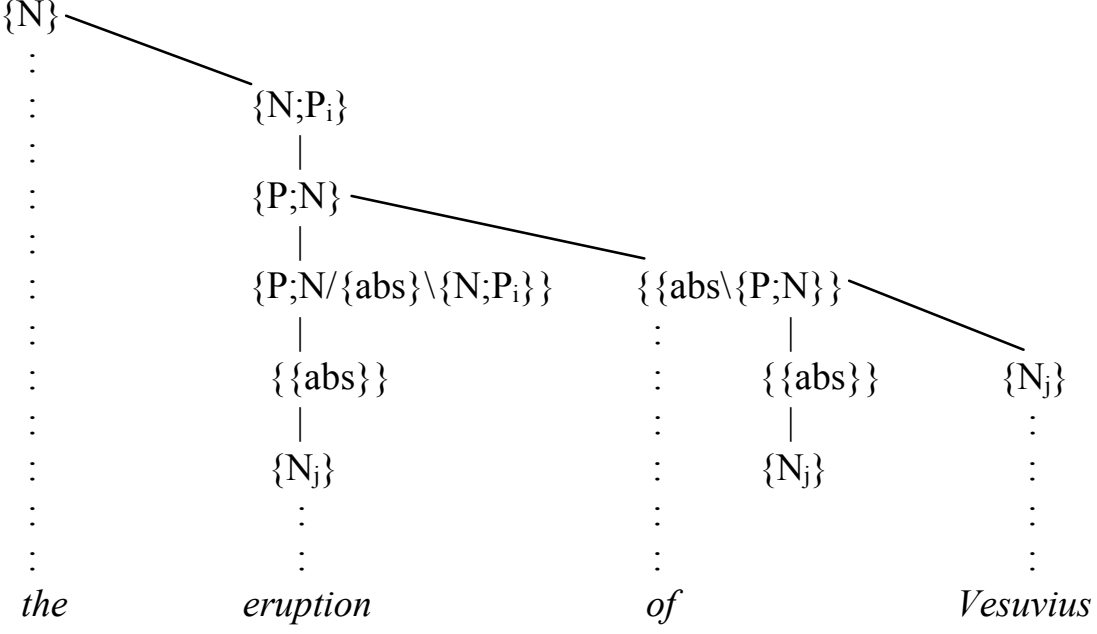

b.

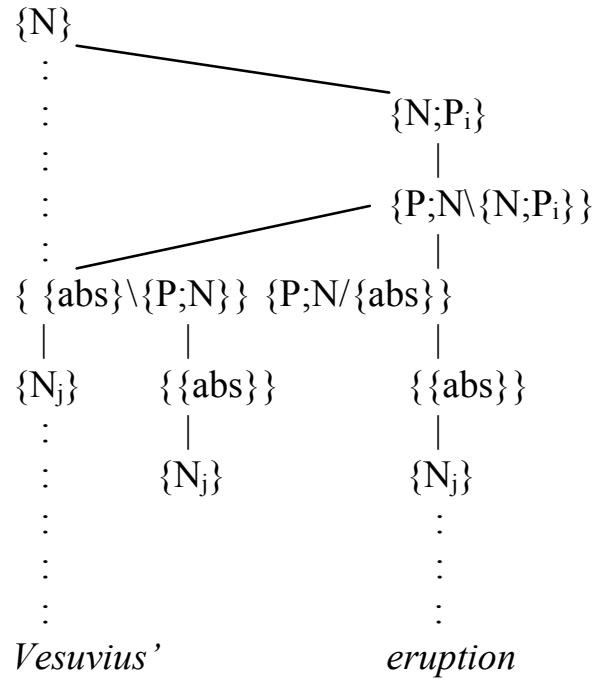




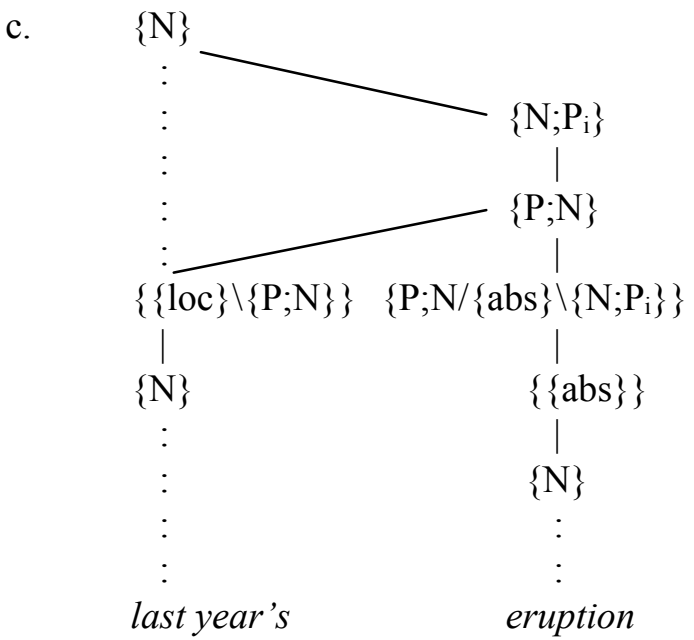

I have represented the participant of the verb in these as simply absolutive, but it is alternatively interpretable as also agentive. In all of these representations the base is associated with the dependent category, the verb, and the required category of the absorbed head, i.e. noun, is marked by the suffix, as represented in (19) or (20). The first two of these introduce the assumption that the apparent participants of the derived noun are in apposition with an incorporated participant and are thus optional (cf. Anderson 2011a: §5.4).

(29a) and (b) also reveal, by their differences, that in such nominalizations what would be selected as the subject of the corresponding verb may or may not appear in the distinctive genitive position, and (29c) reveals that the genitive is not reserved for "subjects", as well as illustrating the optionality of the latter. The genitive construction itself, which is also optional (cf. (29a) with a simple definite determiner), involves a definite determiner that is associated lexically with a functor which has in turn been absorbed by a nominal, a name in these cases. However, syntactically the functor is connected to a verb, either as participant or circumstantial and the verb has absorbed a noun, the noun that satisfies the valency of the determiner. The genitive thus fuses two different syntactic roles in relation to the noun (for some discussion see Anderson 2006: $\S 10.3 .3$ ). In both (29b) and (c) the lower functor is provided by an argument of the subjoined verb.

With ordinary "possessive" genitives, like that in Bertie's hat, the functor is an independent locative that has absorbed the definite determiner, as shown in (30): 
30)

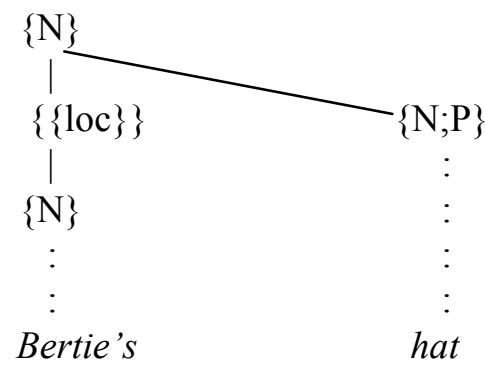

There is no category subjoined to the $\{\mathrm{N} ; \mathrm{P}\}$ that the locative Bertie is an argument of. In all of (29)-(30) I have ignored the partitive relation between the $\{\mathrm{N} ; \mathrm{P}\}$ and the upper $\{\mathrm{N}\}$, as well as the definiteness of the latter

In (29) the noun is marked morphologically as derived from a verbal base. Misfortune and mischief, however, though morphologically complex, afford no evidence of a verbal base. But, as well as denoting an event or events, they too exhibit the participants and circumstantials that we found with the overtly deverbal form. Consider, for example, Nigel's misfortunes/mischief, the misfortunes/mischief of Nigel, and last year's misfortunes/mischief. Notice too that the prefix mis- is typically attached to verbal bases or to nominal ones that are morphologically derived or are the result of conversion from verbs. We find morphological derivation from a verbal base with such as misinformation and misbehaviour, and conversion from a verb with a noun like mistake. Distributionally and semantically similar nominals like misfortune and mischief lack a source for a verbal base. But they are nevertheless compatible with the generalization concerning mis- if their nominal categorization has a verbal categorization subjoined to it. They are non-derived absorptions, and representations like those in (29) are appropriate to their characterization. The valency of the component $\{\mathrm{P} ; \mathrm{N}\}$ can be deduced from what is allowed to the immediate syntax of the noun, on the assumption that it is, as elsewhere, the subjoined $\{\mathrm{P} ; \mathrm{N}\}$ that determines the presence with such complex nouns of elements that are not associated with prototypical nouns.

Mischief lacks a transparent base of any kind. But the overt base of misfortune is the "event" sense of the noun fortune, which is apparently underived. However, it too shows arguments appropriate to a verbal head, as in Basil's fortunes while at the gambling table. It thus illustrates a complex internal categorial structure that is not derived: there is no eligible base either morphological or conversional. This is typical of apparently underived "event" nouns. Here also belong "event" nouns such as accident, whose morphological complexity is for many users of English far from transparent, and for everybody else etymological only.

We find a similar situation with, for instance, such "mental state" nouns as belief and faith. They too are also notionally non-prototypical, and they have a 
verb-like argument structure. Consider Fred's beliefffaith in himself. Belief also takes a verbal prefix (as in behead, bedevil, befoul), even though the combination is scarcely compositional. And it has a plausible, if irregular, source for a verbal base in the shape of the verb believe. The noun trust, on the other hand, is converted, but it too has a source. Representations similar to those in (29) are again suitable for belief and trust - as well as for faith, where there is, as with fortune and misfortune, no corresponding verb, and the presence of the nounderiving suffix -th is particularly opaque in its case. I suggest that faith has the synchronic status of non-derived item in a typical mental lexicon.

Both fortune and faith have an "unmotivated" base; it is categorial only, and not expounded either in the form of the nouns themselves or of a source verb.

These "mental-state" nouns also participate in what can perhaps be seen as a syntactic alternative to derivationality and conversion, in the form of lexical periphrases. In commenting on such phrases as take a walk and have a shower, Anderson (2011b: 107) suggests:

\begin{abstract}
Such phrases are perhaps the most obvious kind of candidate for the title "lexical periphrasis", rather than just "idiom" or "paraphrase". They come closest to resembling a grammatical periphrasis such as ... monita/monitus est 's/he was reminded'. This resemblance resides in the lexical periphrasis ... involving a semantically simple verb and its object, where the verb resembles an affix in "deriving" a verbal sequence from a noun ... But it ... involves an equivalence between a sequence of words, or indeed lexical items, and a word or lexical item, and not an equivalence of some sort between a sequence of words and a word form.
\end{abstract}

In the present case such a periphrasis can provide a "compensatory" verbal construction for a noun like faith, as in Fred has faith in his own abilities.

I conclude this section with a look at "human" - mostly agentive or "experiencer" - nouns, which display interesting differences from the types we have just been looking at. I suggested in $\S 2$ that we could represent the deverbal conversion illustrated by the "human" noun cook as in (14):

14)

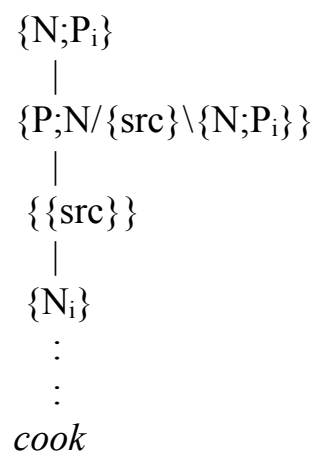


Such nouns display less capacity for making manifest the valency of the base category. In the first place, the major participant is incorporated, as shown in (14). Also the other participant of the verb that is the source of the base is often indefinite, and so not overtly expressed. I have for this reason silently omitted the absolutive argument of the verb category in (14). Further, such derived nouns are close to prototypical nouns: they denote a stable discrete entity, and are less compatible with the dynamic circumstantials associated with verbs and "event" nouns, and their discreteness, or non-relationality, reinforces the tendency not to express the participants of the verbal base.

Expression of relationality tends to be accommodated by noun compounding, without overt expression of functors - as in pastry-cook. Here the absolutive expressed by of in (29a) is absorbed by the initial nominal - as represented in (31), which representation also remedies the omission in this part of the verbal valency in (14):

31)

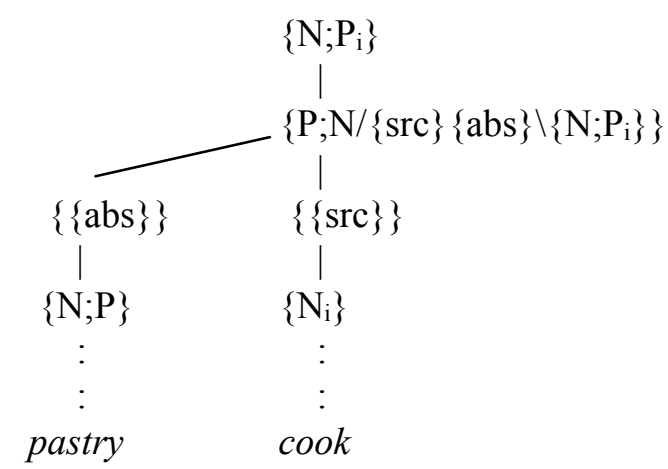

The preposed noun is directly absorbed by the functor, in that it is nonreferential, and so lacks a governing determiner.

"Human" nouns that are based on verbs that more commonly express two participants show both the possibilities displayed in woman-hater and hater of women, particularly if the derivation is marked morphologically, as in the present case. We might represent the latter as in (32), which is partially syntactic, while the former conforms to (31): 
32)

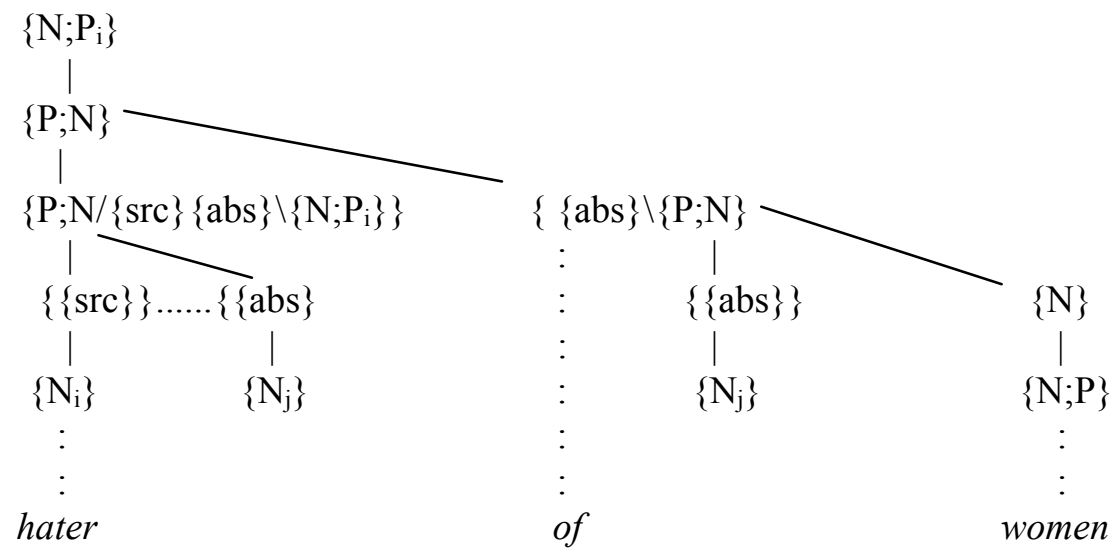

(32) recognizes that both arguments of the verb are incorporated: the horizontal dotted line indicates lack of serialization; the of-phrase is apposed to the verb and its $\{\mathrm{N}\}$ is coreferential with the incorporated absolutive $\{\mathrm{N}\}$. The noun in (32) is referential, and therefore has absorbed a determiner. We have an overt determiner in hater of those women. The noun compound version, unsurprisingly, often suggests more permanence, and even a professional status: compare prison-visitor vs. visitor of prisons - or visitor to prisons, both of which could suggest some kind of sadistic tourist.

"Human" nouns that are neither morphologically nor conversionally derived but have notional affinities with derived forms afford evidence of internal verbal categorization. But, the expression assassin of the president strikes me as rather less felicitous than, say, murderer/killer of the president - though happy with the "event" construction in assassination of the president: assassin. But such underived nouns "human" nouns readily accept adjectival modifiers that are equivalent to characteristic circumstantial modifiers of the putative verbtype of the covert base. Compare He's a former assassin with He formerly murdered important people - or, with the causative based on the noun, He formerly assassinated people. Or, more frivolously, compare He's a part-time assassin with He murders people part-time. This would correlate well with a partial lexical representation for assassin of the form shown in (33): 
33)

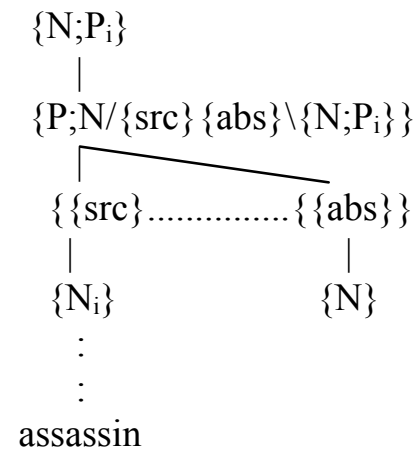

Once more the dotted horizontal linking the functors governing the two $\{\mathrm{N}\} \mathrm{s}$ indicate that both the paths initiated by them are subjoined to $\{\mathrm{P} ; \mathrm{N}\}$; linearization does not apply to the categories in (33).

More striking is a form whose morphology is to most users synchronically obscure - apart from the final suffix, perhaps - but which offers a fully lexical equivalent to the complete (morphological and syntactic) representation in (32) - the form misogynist. This is based etymologically on Greek equivalents of the elements in woman-hater (though differently linearized). And the categorial configuration remains lexically relevant, even if only in the selection of circumstantials. I represent this configuration as in (34):

34)

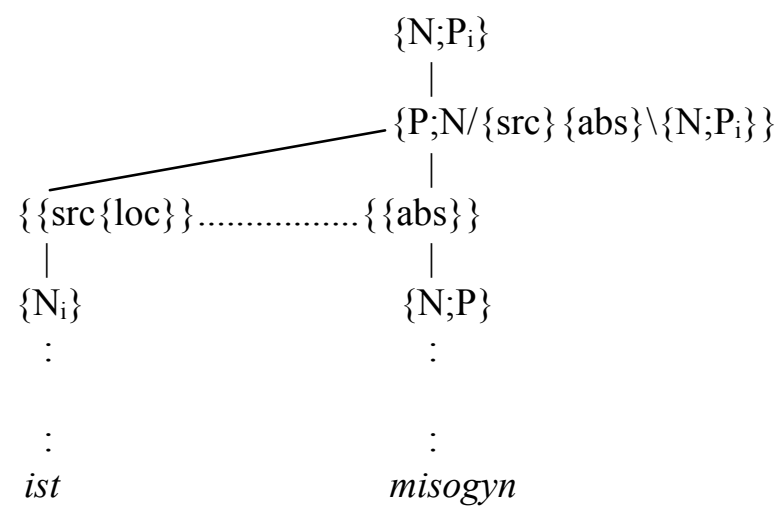

Compare here the circumstantials in She is a fervent misogynist with She fervently hates women. The sequencing of affix and its base is determined morphophonologically. Similarly, the series people-eaters, anthropophagi, and cannibals show decreasing transparency, but all three select as modifiers equivalents to circumstantials such as those in They eat people occasionally/ voraciously. It is not that these expressions are necessarily synonymous, but that they share a categorial configuration. 
This concludes the present section on the semantics and syntax of certain types of non-derived noun, and the evidence their behaviour provides for the presence of a covert verbal base. The representations offered are partial and simplified. For instance, the absolutive argument in (32) is taken by Anderson (2006: §10.3.1) to be an optional element that is in apposition to an incorporated coreferential participant rather than being a participant, as suggested, for simplicity of presentation, in (32), and as it would be in She hates women (see too Anderson 2011a: §2.4). This is recognized in the structure given in (29a), for instance. The following section offers further evidence, from another area, for the presence in the lexicon of such covert categorial complexity.

\section{Lexical causatives}

The verbal basis for the complex nouns we've been looking at is most obviously evidenced in their valency, combined with their notional non-prototypicality. There are also motivations from valency for interpreting some non-derived verbs as involving absorption of a verb by a verb, particularly causatives; but it is of a rather different character. Strikingly, English lacks productive overt morphological mechanisms for deriving verbs from verbs, though conversions are not uncommon. The latter are illustrated particularly by causatives such as that in We walked the horses back to the paddock, with a causative converted from an intransitive. But in English lexical causatives - covert absorptions of a causative $\{\mathrm{P} ; \mathrm{N}\}$ - cover part of the same territory as the morphological causative systems found in languages like Turkish. So putative deverbal lexical causatives in English can be compared with the results of the valency relationships that are marked morphologically in other languages.

Limitations on the resources of a language for differentiating the different participants of a single verb inhibits the elaboration of morphological causatives. Thus, in Turkish, the subject of the intransitive in (35a) corresponds to the accusative in the derived causative of (35b), and the subject of the transitive in (35c) corresponds to the dative of (35d), with the identity of the accusative being constant between the two constructions; but causativization of the ditransitive in $(35 \mathrm{e})$ presents a problem for the participant-differentiating morphological resources of the language:

35) a. Hasan öl- dü

Hasan die-PST

'Hasan died'

b. Ali Hasan-1 öl- dür- dü

Ali Hasan-ACC die-CAUS-PST

'Ali killed Hasan' 

c. Kasap et- i kes-ti
butcher meat-ACC cut-PST
'The butcher cut the meat'
d. Hasan kasab- a et- i kes-tir- di Hasan butcher-DAT meat-ACC cut-CAUS-PST
'Hasan had the butcher cut the meat'
e. Müdür Hasan-a mektub-u göster-di director Hasan-DAT letter- ACC show- PST
'The director showed the letter to Hasan'
f. Dişçi müdür- e mektub-u Hasan-a göster-t- ti dentist director-DAT letter- ACC Hasan-DAT show-CAUS-PST
'The dentist made the director show the letter to Hasan'
g. Dişçi Hasan-a mektub-u müdür tarafindan göster-t- ti dentist Hasan-DAT letter- ACC director by show- CAUS-PST
'The dentist made the director show the letter to Hasan'

With causativization of ditransitives, preservation of the morphological character of expression of causativity is maintained by some speakers at the cost of doubling the dative, as in (35f). But many speakers prefer the analytic construction in $(35 \mathrm{~g})$ for signalling which participant corresponds to the subject of (35e). It involves the postposition otherwise used to introduce the passive agent (which is not a participant). For discussion and references, see Anderson (2005, 2011b: 287-9).

Lexical causatives in English lack not just causative morphology, but also nominal case morphology. Consequently, they seem to be even more restricted, so that the causative of a traditional ditransitive, such as is illustrated by $(35 \mathrm{f}, \mathrm{g})$ vs. (35e), would have to adopt syntactic means of differentiating it from simple ditransitives. And the same can apparently be said for the causative of agentive transitives, corresponding to (35d) and (35c), respectively. But, on the other hand, in both English and Turkish ditransitives themselves can be argued to be complex: they are causatives, but not the causatives of agentive transitives like (35d). Thus, the göster- of (35e-g) is an irregular causative based on gör- 'see'. The göster-t-ti of (35e-f) is thus doubly causative. The ultimate base gör- or see is a perceptual directional verb. These various observations relate to general constraints on valency that I suggest have a cognitive basis.

Anderson (2006: §13.2.3), for instance, argues that the secondary features of the functor category reduce to the three we have encountered in the preceding: absolutive, locative, and source. In valencies these can combine to designate a particular functor, so that, as we have seen, the agentive intransitive in Bill is working might be characterized as $\{\operatorname{src}\{\mathrm{abs}\}\}$, i.e. an asymmetric combination of absolutive and source of the action. Here absolutive functions as a tertiary 
feature. But, of course, these features also differentiate functors that label different participants in the valency of a predicator: we can differentiate the two arguments in Bill is reading the new book as source of the action vs. absolutive. There are constraints on both kinds of combinations of functor relations, however.

In particular, in a single predication, i.e. as arguments of a simple single predicator category, only absolutive and locative can appear more than once, and locative appears twice only if the occurrences are differentiated as spatial source vs. goal. These are the tertiary features that we find in The book slipped from his hand into the waste-basket: $\{\operatorname{loc}\{\mathrm{src}\}\}$ vs. $\{\operatorname{loc}\{\mathrm{goal}\}$. This restriction means that no simple, mono-categorial predicator contains two sources, whether secondary (of the action) or tertiary (of the movement). \{absolutive\} can appear alone or with another functor, locative or source of the action, or another absolutive (giving an equative, such as Bill is the culprit). The participantdifferentiating resources of a language are typically based on such simple predications. But this may be obscured by the intervention of neutralizing grammaticalizations such as subject-formation - to which we return below.

The nature of these differentiating resources is associated with the absence of lexical causatives of English agentive transitives, compared with the Turkish morphological causative in (35d). In We walked the horses back to the paddock the subordinated relation of the horses can be interpreted, in the first instance, as expressed simply by its appearing in object position rather than subject position it has in The horses walked back to the paddock. In (35b) the subordinated participant is accusative. But a causativized agentive transitive has two potential objects. In Turkish (35d) the subordinated participant is marked with the dative found in ditransitives like that in (35e), which marks a goal locative. But the ditransitive and causativized transitive are distinguished by the verbal morphology: only the latter is a regular causative. English too has a ditransitive construction that would serve the purpose of allowing for a subordinated source of the action, but it is pre-empted by the ditransitive, another variety of causative: the causative of a directional that is exemplified by show - or the göster- of (35e). In English there is no differentiating causative morphology. It is these directional causatives in English that are the illustration of covert complex categoriality whose explication this section aims at.

Firstly, however, further on restrictions in valency, we should observe that secondary source and locative do not appear in the same predication with the same status: one must be subordinated to the other. So we find as well as $\{\operatorname{loc}\{\operatorname{src}\}\}$ the $\{\operatorname{src}\{l o c\}\}$ in the "experiencer" subject of Frieda knows that. That there is such combinatory restriction seems to be because the presence of the secondaries source of the action and locative defines distinct cognitive event-types, action vs. location, which cannot be combined without subordina- 
tion of one to the other, as in $\{\operatorname{loc}\{\operatorname{src}\}\}$ and $\{\operatorname{src}\{\operatorname{loc}\}\}$. This is what accounts for the necessarily complex lexical structure of the verb in simple sentences with distinct source of the action, absolutive, and locative arguments, including sentences with datives or their equivalent.

The various combinations and the groupings suggested above that are most relevant here are shown in table III (for a more comprehensive picture see again Anderson 2006: §13.2.3, also 2011a: §.5).

Table 3. Combinations of semantic relations

\begin{tabular}{l|c|c|c} 
& actional domain & abs & locational domain \\
basic & $\operatorname{src}+$ abs $\operatorname{src}\{\mathrm{abs}\}$ & $\mathrm{abs}+\mathrm{abs}$ & $\operatorname{loc}\{\mathrm{abs}\} \operatorname{loc}+\mathrm{abs}$ \\
\hline & mental domain & \multicolumn{2}{|c|}{$\operatorname{directional~domain}$} \\
mingling & $\operatorname{src}\{\operatorname{loc}\}$ & $\operatorname{loc}\{\operatorname{src}\}+\operatorname{loc}\{$ goal $\}$
\end{tabular}

The braces enclose tertiary features, and '+' joins relations attributed to distinct functors. The upper level in the table distinguishes agentive transitives, agentive intransitives, simple intransitives and equatives (grouped in the middle box), "intransitive" (holistic) locationals (as in The place is swarming (with police)), and locational "transitives". The table also identifies the two domains that intersect only in characterizing a single functor, as indicated in the second level. As concerns this second level, the addition to a source of a tertiary locative attenuates the action, restricting it to the mental domain, thus giving an "experiencer"; and the addition of source/goal to locative introduces directionality. I have ignored the role of absolutive in valencies that involve mingling of the two domains.

Also, 'abs + abs' is noted as a possible valency (that for equatives); but absent from table III, as disallowed, is a combination of 'src + src', as well as 'src + loc', whereas distinct locatives can appear in the valency of a single predicator provided they are differentiated as goal and source. These restrictions are a reflection of the cognitive complexity of an event involving two sources of the action, as well as one involving action and location. Linguistic representation of such scenes must involve more than one predication. In particular a locative scene that is accompanied by a distinct agentive source involves a locative predicator subordinate to a causative. Lexical causatives are thus necessarily categorially complex: the range of arguments demands this. Let me try to make the representational consequences of this more concrete.

The non-agentive directional sentence The book slipped from his hand into the waste-basket has a single verbal category, with three participants, as indicated in (36), (which pays no attention to the structure of determiner phrases): 
36)

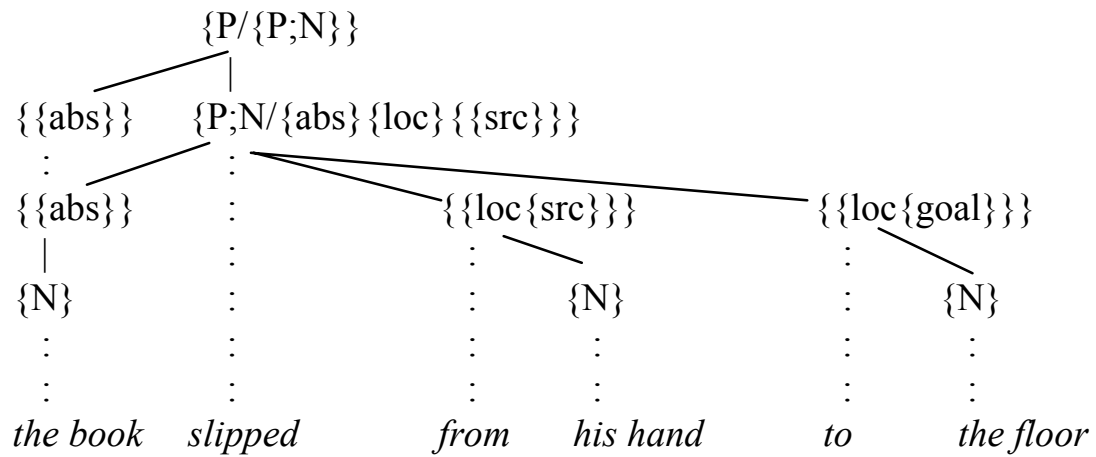

Once again (recall (10) above), the absolutive of $\{\mathrm{P} ; \mathrm{N}\}$ shares its argument with the absolutive of $\{\mathrm{P}\}$, which is not part of the valency of $\{\mathrm{P}\}$, but is introduced by a requirement that syntactically a predicator must have a dependent absolutive (see again Anderson 2006: §11.2). The book appears to the left of its head(s), unlike the non-subject complements of slipped. The functor specifications fill in the redundancies omitted from the valency, so that ' $\{\{\mathrm{src}\}\}$ ' corresponds to ' $\{\{\operatorname{loc}\{\operatorname{src}\}\}\}$ ', and in the presence of $\{\{\operatorname{src}\}\}$ ' $\{\operatorname{loc}\}$ ' is filled out as ' $\{\{$ loc $\{$ goal $\}\}\}$ '

However, the agentive sentence in (37) (where, for clarity, I have omitted even the determiners themselves) has a complex verb, a causative converted from the simple verb in (36):

37)

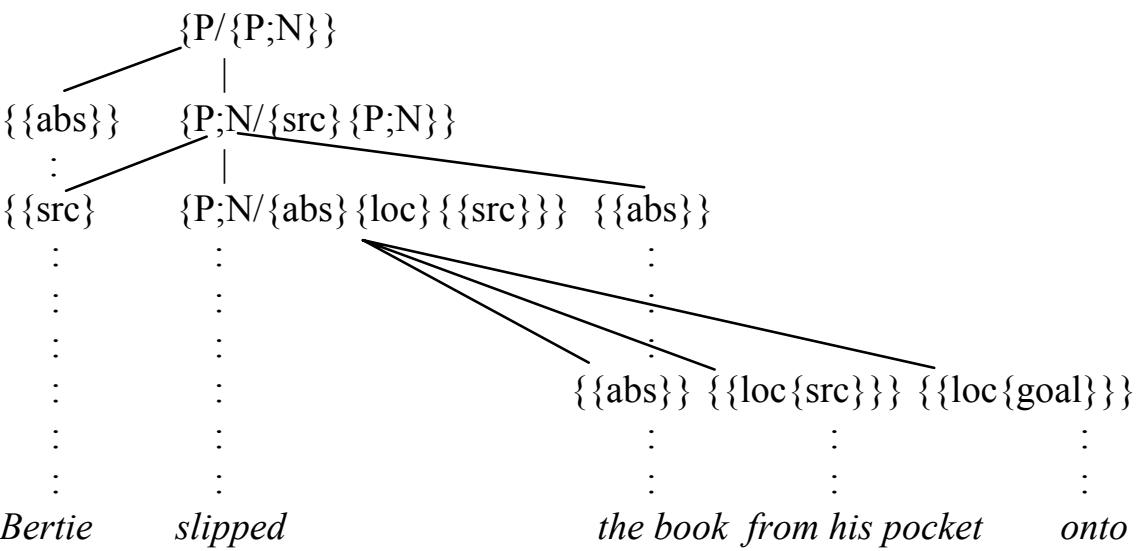

the table

The top two absolutive functors - those dependent on $\{\mathrm{P}\}$ and on the upper $\{\mathrm{P} ; \mathrm{N}\}$ - are not categorized for; they are not part of the valency of the predicator they depend on. They both host functors that are subcategorized for, and the first of which is thereby "raised" to the left of $\{\mathrm{P}\}$ (see yet again Anderson 
2006: §11.2). A single predicator cannot support both transitive action and location. Configurationally, the converted causative conforms to the structure of a syntactic causative such as that in (38):

38)

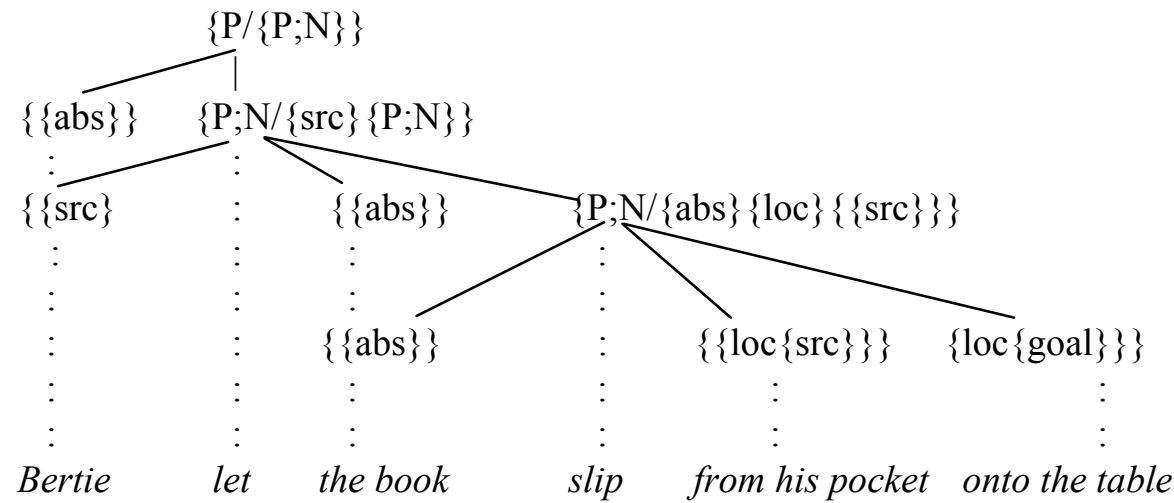

But what is more germane here is that the same constraints on combination apply to lexical, covert causatives.

Thus, a sentence like Bertie took the book from his desk to the window warrants the same structure as is given to the conversion in (37). Moreover, "dative" sentences such as Bertie taught the class that course also, since they too involve action and directionality, manifest a variant of such a structure. Closer to (37), however, is the structure of Bertie taught that course to the class, which I give as (39):

39)

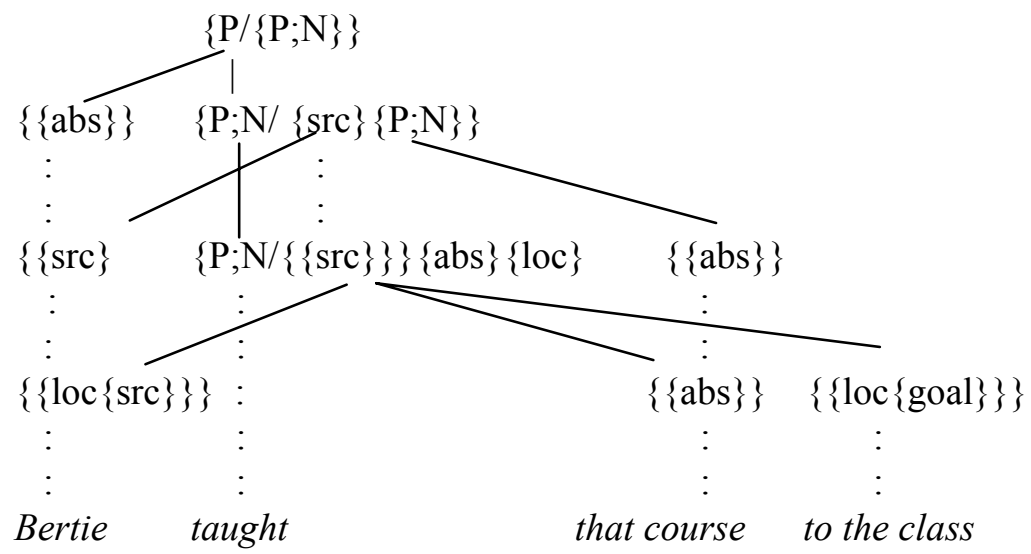

(39) differs from (37) only in that in the lexical representation for the verb the source of the action of the upper $\{\mathrm{P} ; \mathrm{N}\}$ is linked to the tertiary source of the lower $\{\mathrm{P} ; \mathrm{N}\}$, and they thus share the same argument, realized as Bertie. That is, 
the linking is specified in the valency of the complex verb, as shown in (39) (see further Anderson 2006: §13.2.2 on lexical argument linking).

In the corresponding "dative" sentence, the goal locative is an "experiencer", as in (40):

40)

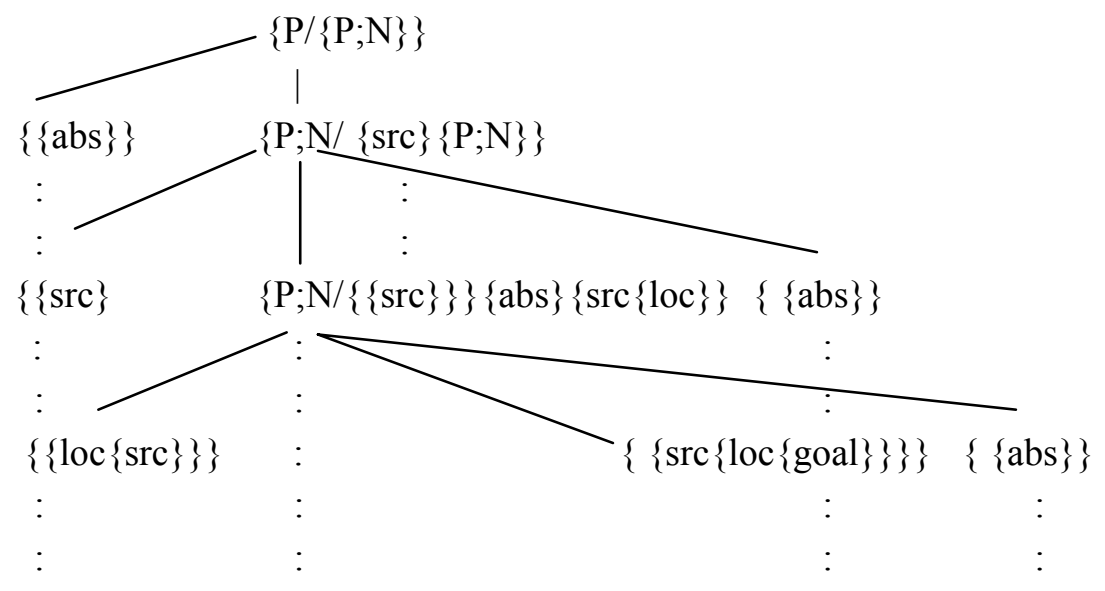

Bertie taught the class that course

As a secondary source, a goal "experiencer", the class "outranks" the absolutive that course, and therefore it is the former that shares its argument with the unsubcategorized-for absolutive of the agentive predicator. In the case of teach the "experiencer"/non-"experiencer" difference is reflected in the relative acceptability of Bertie taught that course to an empty room and *Bertie taught an empty room that course. The "experiencer" introduces a presupposition of experiential involvement of some sort that is not present with the non-"experiencer".

This same involvement is observed in the simple - but "experiential" - directional of (41): 
41)

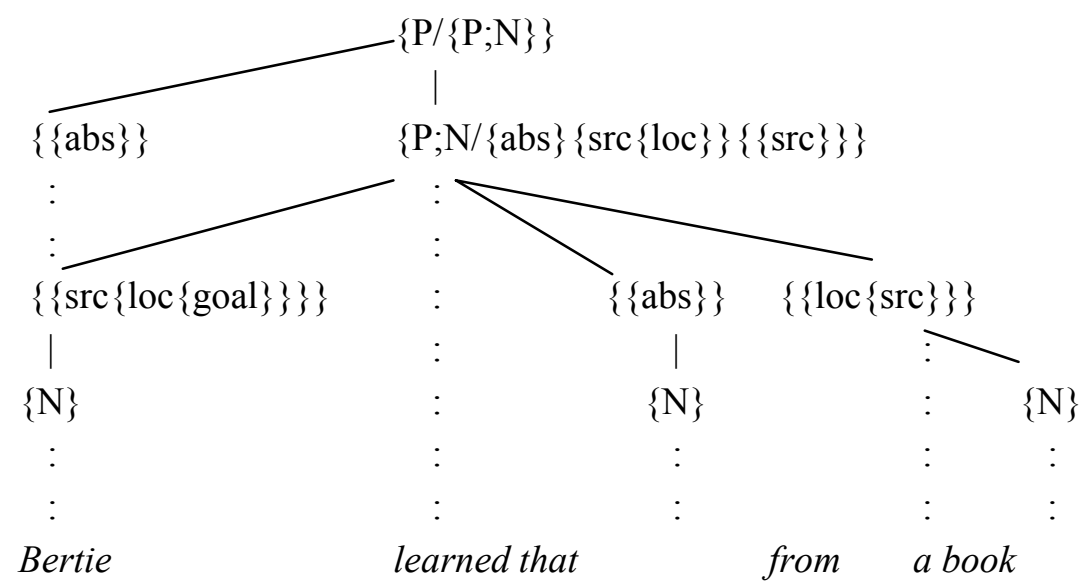

As with the dative in (40), Bertie realizes a positively-oriented (goal) directional "experiencer"; and the representation of the functor thus includes a quaternary feature, the goal. Degrees of feature subordination superior to this are of a complexity that makes them less and less likely to be encountered in language.

The above representations for lexical causatives are another manifestation of the mutual exclusiveness of the locational and transitive actional domains that underlies syntactic and morphological causatives. But, as we have seen, the English lexical causative is even more restricted. There is nothing corresponding to Turkish (35d), the causative of the transitive in (35c), recalled here
c. Kasap et- i kes-ti
butcher meat-ACC cut-PST
'The butcher cut the meat'
d. Hasan kasab- a et- i kes-tir- di Hasan butcher-DAT meat-ACC cut- CAUS-PST
'Hasan had the butcher cut the meat'

As we have also seen, morphological causativization in Turkish even contrives a causative of "dative" verbs like that in (35e), which are themselves causative, even though the form in (35e) is perhaps sufficiently obscured to count as a lexical causative:

$$
\begin{aligned}
& \text { e. Müdür Hasan-a mektub-u göster-di } \\
& \text { director Hasan-DAT letter- ACC show- PST } \\
& \text { 'The director showed the letter to Hasan' }
\end{aligned}
$$



f. Dişçi müdür- e mektub-u Hasan-a göster-t- ti dentist director-DAT letter- ACC Hasan-DAT show- CAUS-PST 'The dentist made the director show the letter to Hasan' g. Dişçi Hasan-a mektub-u müdür tarafindan göster-t- ti dentist Hasan-DAT letter- ACC director by show- CAUS-PST 'The dentist made the director show the letter to Hasan'

Along with other causatives that include subjoined agentive transitives, lexical causatives of "dative" verbs are absent from English.

This means that the lexical configuration in (42) is disqualified, unless the configuration is morphologically derived:

42)

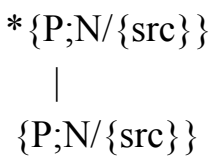

In the latter circumstance, Anderson (2005: especially §4) suggests that the functor realized as the "dative" in (35d) is supplied, as part of causativization, with (in present terms) a tertiary locative, giving as a representation of the "dative" $\{\{\operatorname{src}\{l o c\}\}\}$ rather than simply $\{\{\operatorname{src}\}\}$. This general redundancy affecting causatives can be as expressed in (43), where 'subj' is the specification of the argument in the valency of the lower verb that is highest on the subjectselection hierarchy:

$$
\begin{array}{ll}
\{\mathrm{P} ; \mathrm{N} /\{\operatorname{src}\}\} \\
\mid \\
\{\mathrm{P} ; \mathrm{N} /\{\operatorname{subj}\}\}
\end{array} \quad \Leftrightarrow \quad \begin{gathered}
\{\mathrm{P} ; \mathrm{N} /\{\operatorname{src}\}\} \\
\mid \mathrm{P} ; \mathrm{N} /\{\text { subj }, \text { loc }\}\}
\end{gathered}
$$

In the case of (35d) 'subj' = 'src'. In these terms, causativized absolutive subjects, as with Bertie dropped the book on the floor, become affecteds - i.e. \{ $\{$ abs $\{10 c\}\}\}-$ a kind of patient. And causativized intransitive agents, such as the horses in We walked the horses back to the paddock, we can now interpret as also marked as patient by (43) - in this case as $\{\{\operatorname{src}\{\operatorname{abs}\{10 c\}\}\}\}$. Patients as a whole can be defined as $\{$ non-loc $\{l o c\}\}\}$ (see for some discussion Anderson 2006: §6.2, 9.1, 2011a: §.5); so, "experiencers", characterized as \{ $\{\mathrm{src}$ $\{1 \mathrm{oc}\}\}\}$, are also patients.

However, in the case of potential English lexical causatives of agentive transitives, (43) does not apply, and they would infringe (42). Thus, apart from anything else, it is apparent that (43) avoids infringement of (42) in Turkish mor- 
phological causatives of transitive agentives - if (42) is otherwise assumed to apply quite generally in the lexicon rather than being restricted to non-derived lexical items, with covert internal structure. If, on the other hand, (43) is lacking with English putative lexical causatives, then covert causatives of transitive agentives will be blocked. It appears, then, that application of (43) depends on the presence of overt expression of causative status by morphology or in the form of a syntactic causative construction (as in, say, French). The interesting question this raises is this: how general in language is the failure of (43) to apply to lexical causatives, and consequently how general is the absence of lexical causatives of transitive agentives? This is part of the more general question of how and how much covert lexical complexity differs from derived representations in constraints on structure. I suggest that pursuit of such a question depends on an adequate formulation of argument-differentiating resources in language.

\section{Conclusion}

Here I have used the distinction between absorption and incorporation as the starting-point for a discussion of lexical complexity in categorization. The complexity I have confronted has been only that of minimal signs - signs that have only one base (unlike compounds) and no internal syntactic structure (unlike idioms - see e.g. Anderson 2011b: §3.1.1). In prototypical incorporation the base has subjoined to it a functional category or categories; in absorption the base is subjoined to another primary, functional or contentive, category, resulting in "category change". Both complexities may be manifested by the presence of particular inflectional categories, but only absorption is derivational.

If the derivation is not marked morphologically we have conversion, in which case only the syntax and possibly the presence of "alien" inflectional categories signal the category difference. Derivational morphology involves modifications to the expression of the base, either by affixation or by internal alteration in the form of the base. Absorption of a functional category respects the valency of the absorbed category: thus, verbs satisfy the valency of operatives, and may absorb them. But reflection of valency in absorption of a contentive category by another is variable in character. And indeed nouns derived from verbs may have the verb apposed to them rather than serving some valency-based function. This variation was illustrated by a look at different derivational processes.

In the latter part of the discussion we were concerned with covert lexical complexity. There is lacking in this case any internal indication of derivationality of a particular sign. Rather, the non-prototypicality of its distribution matches the non-prototypicality of its semantics and can be most transparently 
accounted for by a complex categorial structure, especially when we can associate the particular complexity with overtly derived forms. We proceeded to a consideration of this via a brief look in $\S 5$ at the intermediate case of "collateral" adjectives, where a morphologically derived form has a "semantic correlate" for the base of the adjective that is different in expression from that base. In appealing to "suppletion" here, we recognize the centrality in grammar of categorial structures based on semantic relationships. The sections on covert lexical structure (§§6-7) exploit just this recognition, but more radically. They relate the complex semantically-based categorial structures of some non-derived minimal signs to a distributional behaviour that is suggestive of a derived form.

This is particularly salient in the discussion of lexical causatives in the last section. These share semantic and syntactic properties with morphological causatives (and, indeed, syntactic causatives). However, the range of possibilities, in English at least, is more restricted, with causatives of transitive agentives being disfavoured. It is suggested that this is related to stricter application of constraints on valency, in the absence of morphological or syntactic expression of causativization.

Some of the regularity and irregularity that is associated with both the categoriality and realization of complex lexical items is illustrated by familiar nouns of perception. Thus, corresponding to the perception verb in (44a) we have the converted noun in (44b), where the source of the smell may be expressed, but not usually the "experiencer" of the smell:

44) a. Bertha smelled the rose

b. the smell of the rose

Similar are the pair in (45):

45) a. Rover tasted the biscuit

b. the taste of the biscuit

However, the perception noun in (46b) is realizationally unrelated to the verb of (46a):

46) a. Stuart heard the explosion

b. the sound of the explosion

And the 'derivation' in (47b) is obscure, if we take the verb in (47a) to be the base: 
47) a. They saw their cousin

b. the sight of their cousin

Only less everyday nouns of perception, such as perception, show more transparent derivationality. The grouping of (44) and (45) may reflect the related modularity of perception involved in both cases. Smell and particularly taste normally involve close proximity, even contact, of the participants. This is also the case with the verbs feel and touch, which also allow derivation of a noun by conversion.

However, though taste and smell - and hear and see - involve a dedicated instrument (or 'organ'), feel and touch may involve different instruments, though this is not always specified, and though with touch particularly use of the hand is unmarked. This is illustrated by (48), with optional circumstantials:

48) a. She felt the bottom (with her foot)

b. He touched the button (with his finger)

The feel noun behaves like the other perception nouns in suppressing the "experiencer" and usually an instrument, as in (49a):

49) a. the feel of the bottom

b. the touch of his finger on the button

But (49b) shows equivalents of both the instrumental and the contact locative.

In all of these cases an -ing noun allows expression of the "experiencer", and even an agentive interpretation, given a suitable context, and in general these productive morphologically overt derivations reflect the valency of the verbs more faithfully:

50) a. Bertha's smelling of the rose

b. Rover's tasting of the biscuit

c. Stuart's hearing of the explosion

d. their seeing of their cousin

e. her feeling of the bottom (with her foot)

f. his touching of the button (with his finger)

But (50c) allows an additional interpretation where the of is roughly equivalent to about. But overall what is striking about similarities and differences with these categorially complex nouns is the role of the base verb in understanding 
the elements that can accompany them. This is true of the aspects of perception words that I have selected and of such other aspects as the directionality of the type of perception involved, not to mention other aspects of the representation of perception such as its interaction with agentivity. But enough is enough!

\section{REFERENCES}

Anderson, John M.

1970 "'Ablaut' in the synchronic phonology of the Old English strong verb", Indogermanische Forschungen 75: 166-97.

1984 Case grammar and the lexicon. University of Ulster: Occasional Papers on Linguistics and Language Learning, 10.

1997 A notional theory of syntactic categories. Cambridge: Cambridge University Press.

1998 "A core morphology for Old English verbs", English Language and Linguistics 2: 199-222.

2005 "The argument structure of morphological causatives", Poznań Studies in Contemporary Linguistics 40: 27-89.

2006 Modern grammars of case: A retrospective. Oxford: Oxford University Press.

2007 The grammar of names. Oxford: Oxford University Press.

2011a The substance of language, 1: The domain of syntax. Oxford: Oxford University Press.

2011b The substance of language, 2: Morphology, paradigms, and periphrases. Oxford: Oxford University Press.

2011c "Referentiality and the noun", Hermes 47: 13-29.

Anderson, Stephen R.

1992 A-morphous morphology. Cambridge: Cambridge University Press.

Colman, Fran

1996 "Morphology: Old and Middle English derivational and inflectional", in: Jacek Fisiak (ed.), 3-28.

nd. The Old English onomasticon: Names and the grammar. MS

Colman, Fran - John M. Anderson

2004 "On metonymy as word-formation: With special reference to Old English", English Studies 85: 547-65.

Dalton-Puffer, Christiane

1992 “A view on Middle English derivation: verbs", VIEWS 1: 3-15.

1993 "How distinct are inflection and derivation? Reply to Lass and Ritt", VIEWS 2: 40-44.

Fisiak, Jacek (ed.)

1996 Middle English miscellany: From vocabulary to linguistic variation. Poznań: Motivex.

Giegerich, Heinz J. - Geoffrey K. Pullum

2010 Foreword to Koshiishi (2010), xiii-xiv.

Kastovsky, Dieter

1993 "Inflection, derivation and zero - or: what makes OE and German derived denominal verbs verbs?”, VIEWS 2: 71-81. 
Koshiishi, Tetsuya

2010 Collateral adjectives and related issues. Bern: Peter Lang.

Lass, Roger

1993a “Old English -ian: Inflectional or derivational?”, VIEWS 2: 26-34.

1993b “Old English class II: More views”, VIEWS 2: 104-10.

Malicka-Kleparska, Anna

1988 Rules and lexicalisations. Selected English nominals. Lublin: Redakcja Wydawnictw KUL.

Matthews, Peter

1974 Morphology. Cambridge: Cambridge University Press.

2001 A short history of structural linguistics. Cambridge: Cambridge University Press.

Pyles, Thomas - John Algeo

1970 English: An introduction to language. San Diego: Harcourt, Brace, Jovanovich. Ritt, Nikolaus

1993 "What exactly is it that makes OE -ian derivational? Reply to Lass", VIEWS 2: 35-9.

Saussure, Ferdinand de

1916 Cours de linguistique générale, (ed. by C. Bally \& A. Sechehaye, with the collaboration of A. Riedlinger. Lausanne \& Paris: Payot.) (2nd ed., Paris: Payot, 1922; 3rd and last corrected ed., 1931.) 